\title{
Pain neurophysiology education improves cognitions, pain thresholds, and movement performance in people with chronic whiplash: A pilot study
}

\author{
Jessica Van Oosterwijck, MS; ${ }^{1-3}$ Jo Nijs, PhD; $;^{1-3^{*}}$ Mira Meeus, PhD $;^{1-2}$ Steven Truijen, PhD, MSc; ${ }^{2}$ Julie \\ Craps, MS; ${ }^{2}$ Nick Van den Keybus, MS; ${ }^{2}$ Lorna Paul, $\mathbf{P h D}^{4}$ \\ ${ }^{1}$ Department of Human Physiology, Faculty of Physical Education \& Physiotherapy, Vrije Universiteit Brussel, Brussels, \\ Belgium; ${ }^{2}$ Division of Musculoskeletal Physiotherapy, Department of Health Care Sciences, Artesis University College \\ of Antwerp, Antwerp, Belgium; ${ }^{3}$ Department of Physical Medicine and Physiotherapy, University Hospital Brussels, \\ Brussels, Belgium; ${ }^{4}$ Nursing and Health Care, Faculty of Medicine, University of Glasgow, Glasgow, United Kingdom
}

\begin{abstract}
Chronic whiplash is a debilitating condition characterized by increased sensitivity to painful stimuli, maladaptive illness beliefs, inappropriate attitudes, and movement dysfunctions. Previous work in people with chronic low back pain and chronic fatigue syndrome indicates that pain neurophysiology education is able to improve illness beliefs and attitudes as well as movement performance. This single-case study (A-B-C design) with six patients with chronic whiplash associated disorders (WAD) was aimed at examining whether education about the neurophysiology of pain is accompanied by changes in symptoms, daily functioning, pain beliefs, and behavior. Periods $\mathrm{A}$ and $\mathrm{C}$ represented assessment periods, while period B consisted of the intervention (pain neurophysiology education). Results showed a significant decrease in kinesiophobia (Tampa Scale for Kinesiophobia), the passive coping strategy of resting (Pain Coping Inventory), self-rated disability (Neck Disability Index), and photophobia (WAD Symptom List). At the same time, significantly increased pain pressure thresholds and improved pain-free movement performance (visual analog scale on Neck Extension Test and Brachial Plexus Provocation Test) were established. Although the current results need to be verified in a randomized, controlled trial, they suggest that education about the physiology of pain is able to increase pain thresholds and improve pain behavior and pain-free movement performance in patients with chronic WAD.
\end{abstract}

Key words: chronic pain, chronic whiplash, cognitions, education, movement performance, pain behavior, pain neurophysiology, pain thresholds, rehabilitation, whiplash associated disorders.

\section{INTRODUCTION}

A whiplash trauma of the neck can result in bony or soft-tissue injuries that produce a large variety of clinical manifestations grouped under the term whiplash associated disorders (WAD) [1]. Using the Quebec Task Force on WAD (QTF-WAD) guidelines [1], WAD can be classified into five grades of severity: grade $0=$ no neck symptoms or physical sign(s); grade I = neck pain, stiffness, or tenderness but no physical sign(s); grade II = neck symptoms and musculoskeletal sign(s) such as decreased range of motion and point tenderness; grade III = neck symptoms and neurologic sign(s); and grade IV = neck symptoms

\footnotetext{
Abbreviations: $\mathrm{BPPT}=$ Brachial Plexus Provocation Test, ES = effect size, NDI = Neck Disability Index, PCI = Pain Coping Inventory, PCS = Pain Catastrophizing Scale, PCS-DV = PCSDutch version, $\mathrm{PPT}=$ pain pressure threshold, $\mathrm{QTF}-\mathrm{WAD}=$ Quebec Task Force on whiplash associated disorders, TSK = Tampa Scale for Kinesiophobia, VAS = visual analog scale, $\mathrm{WAD}=$ whiplash associated disorders .

* Address all correspondence to Jo Nijs, PhD; Vrije Universiteit Brussel, Faculty of Physical Education \& Physiotherapy, Department of Human Physiology, Building L-3rd floor, Pleinlaan 2, BE-1050 Brussels, Belgium; +32-2-629-27-53; fax: +32-2-629-28-76. Email: Jo.Nijs@vub.ac.be

DOI:10.1682/JRRD.2009.12.0206
} 
and fracture or dislocation. Between 10 and 42 percent of patients who sustain a whiplash injury develop chronic pain and approximately 10 percent of patients experience constant severe pain [1-4]. The main pain complaints that persist 6 months after the accident are neck pain (10\%-45\%), headache (8\%-30\%), and pain in the shoulder and arm (5\%-25\%) [5]. Additional complaints by patients with chronic WAD are depression, fear, difficulty concentrating, fatigue, and irritability $[1,6]$.

Little is known about the continuum of WAD from the time of injury through transition to either recovery or chronicity [7]. Several mechanisms such as altered central pain processing and central sensitization [8-11] and the role of cognitions and behaviors [12-15] have been suggested, and evidence that supports these theories is rising. The dearth of trials evaluating conservative treatments for patients with chronic WAD is striking. Stewart stated that very few trials have evaluated interventions for patients with chronic whiplash [16], while Verhagen et al. performed a systematic review concluding that none of the investigated conservative treatments were effective for the treatment of acute, subacute, or chronic symptoms of WAD [17]. The cases that do not recover by 3 months are responsible for the majority of whiplash costs [1]; therefore, treatments that prevent transition to chronicity or that are effective for chronic whiplash have the potential to significantly reduce social and economic costs [15]. Holm et al. suggested that education about the physiology of chronic whiplash pain can improve expectations for recovery, especially in the (sub)acute stages of WAD [18]. This is supported by Oliveira et al., who evaluated the effects of a psychoeducational film shown to patients with acute whiplash who consulted an emergency unit after injury [19]. The film consisted of information about symptomatology, physiology of a cervical strain, physiology and physical/emotional triggers of muscle tension, medical treatment, expectations of recovery, and examples of exercises. This psychoeducational intervention resulted in improved recovery in the patients with subacute whiplash. In patients with chronic WAD, programs including exercise and extensive education to change pain cognitions and pain coping strategies resulted in a positive outcome $[15,20]$.

Catastrophic beliefs about pain are associated with heightened pain and disability in people with chronic WAD and play an important role in the transition from (sub)acute to chronic WAD [12,21-22]. In addition, psychological factors such as depression, anxiety, expecta- tions concerning recovery, and high psychological distress have been identified as important prognostic factors for patients with WAD [7,18,23-24]. Söderlund and Lindberg described the importance of using positive coping strategies in dealing with whiplash-related complaints [22,25]. Patients who are misinformed about pain consider pain to be more threatening and present lower pain tolerance, more catastrophic thoughts, and less adaptive coping strategies [26]. Therefore, the education of pain neurophysiology is aimed at both altering patients' knowledge about their pain states and reconceptualizing pain [27]. Psychoeducational interventions that have been studied in WAD often include informing the patient about symptomatology, recovery, activity, and treatment and/or addressing pain behavior and beliefs. When only cognitive and behavioral responses are encouraged, without reconceptualizing pain, these responses may be counterintuitive for patients with chronic pain because pain is still a sign of harm to them [28]. Therefore, Moseley relies on “deep learning” education on pain neurophysiology that is aimed at reconceptualizing pain, on the assumption that appropriate cognitive and behavioral responses will follow when pain is appraised as less dangerous [29]. Even when education about physiology is included in psychoeducational programs, it is often limited to the physiology of a cervical strain. Except for the changes that occur in the local tissues because of a whiplash injury, changes in local and central pain mechanisms play an important role and should be addressed, especially for patients with chronic pain. Pain neurophysiology education targets this by reconceptualizing the underlying physiological problem of a patient's pain on the assumption that an appropriate cognitive and behavioral/ motor response will follow [28].

Education about the neurophysiology of pain has been studied in chronic pain populations, such as chronic low back pain [27,29-32] and chronic fatigue syndrome [33]. In patients with chronic fatigue syndrome, a single educational session was able to alter cognitions, such as catastrophizing, and pain behavior, such as coping [33]. In patients with chronic low back pain, pain physiology education alters pain beliefs and attitudes and, in conjunction with physiotherapy, improves functional and symptomatic outcomes [27,29-32]. Moseley has also shown that altered pain beliefs are directly associated with altered movement performance, even if no opportunity to be physically active is available [27,32]. This implies that motor performance may be directly limited by pain beliefs. Education about the neurophysiology of 
pain fits within our current understanding of chronic WAD and it might be able to address cognitive emotional sensitization (central hypersensitivity influenced and modulated by cognitions and emotions) in these patients [34]. Taking this into consideration, patient education seems an economical, time-saving method to use in the treatment of WAD. By using education to improve incorrect pain cognitions and attitudes, we might prevent chronicity or improve treatment success.

The single-case study design is often used to systematically evaluate new treatments for specific (usually chronic) patient populations. Hence, it can be used in preparation of a large randomized, controlled clinical trial. One of the crucial features of the single-case design is continuous measurement throughout different conditions, which makes it possible to use individuals as their own controls. The function of the baseline is to describe the present state and predict future projection if no intervention were to take place. By this function, it is possible to judge whether change has occurred from the baseline period to the intervention period. The baseline period of a single-case study typically consists of several baseline assessments that account for the natural variability of the patients' health status. If this (often minimal) variability is suddenly "disturbed" when the intervention is conducted, it is accepted that this is a consequence of the intervention.

Although the use of psychoeducational interventions has been studied in patients with acute WAD, the use of pain neurophysiology education in patients with chronic WAD has not been examined previously. Therefore, the present study is aimed at examining whether two one-onone education sessions about the neurophysiology of pain may lead to a change in pain beliefs and behavior, symptom severity, daily functioning, pain threshold, and movement performance in patients with chronic WAD. The treatment is evaluated using a single-case study design.

\section{METHODS}

\section{Subjects}

We selected patients with WAD grades I to II according to the QTF-WAD [1], who were experiencing chronic pain as result of a whiplash injury, from the medical files available at a university-based department of physical medicine. In WAD grades III to IV, neurological damage, fractures, and dislocations might explain the symptoms experienced by patients, whereas in WAD grades I to II, no physical signs can be identified even when sophisticated imaging techniques are used [35-38]. Given the focus of the education on central sensitization as an explanatory model for WAD symptoms, we deemed it appropriate to limit the study to patients with WAD grades I to II. In addition, when anatomical abnormalities are established, patients are treated by (specialized) physicians, whereas patients without objective signs of tissue damage are referred to a physical therapist for conservative treatment. For these reasons, the study focused on patients with WAD grades I to II. In total, we selected 23 patients experiencing chronic complaints due to a whiplash injury who sought care at a local universitybased clinic. We screened the medical files of these 23 patients according to the inclusion and exclusion criteria of the study. We qualified patients with chronic WAD grades I to II having Dutch as their native language and 18 to 65 years old to participate in the present study. Out of the 23 patients, 11 fulfilled the inclusion criteria. We contacted these patients by telephone and informed them about the study. Six patients agreed to participate in the study, while five patients declined because they were not interested or they had no time to attend the seven study visits.

\section{Procedure}

We invited patients to participate in the study and gave them a detailed information leaflet. The information leaflet stated that the patients were allowed to continue any ongoing treatments but asked them not to initiate any new treatments (medication, rehabilitation, alternative medicine). We then collected patient demographic data (age, time since onset of complaints, medication usage, etc.) using a questionnaire.

This single-case study consisted of an A-B-C design in which periods $A$ and $C$ represent the assessment periods and period B represents the intervention (Figure 1). Period A represents the baseline period, while period C represents the treatment-free follow-up. During the assessment (period A), we asked patients to fill out a battery of questionnaires, i.e., the Neck Disability Index (NDI), the WAD Symptom List, the Pain Catastrophizing Scale (PCS), the Pain Coping Inventory (PCI), and the Tampa Scale for Kinesiophobia (TSK). We also subjected patients to a set of clinical assessments, i.e., the Neck Extension Test, the Brachial Plexus Provocation Test (BPPT), and algometry. We randomized the test order to preclude test-order bias. We randomly allocated patients 


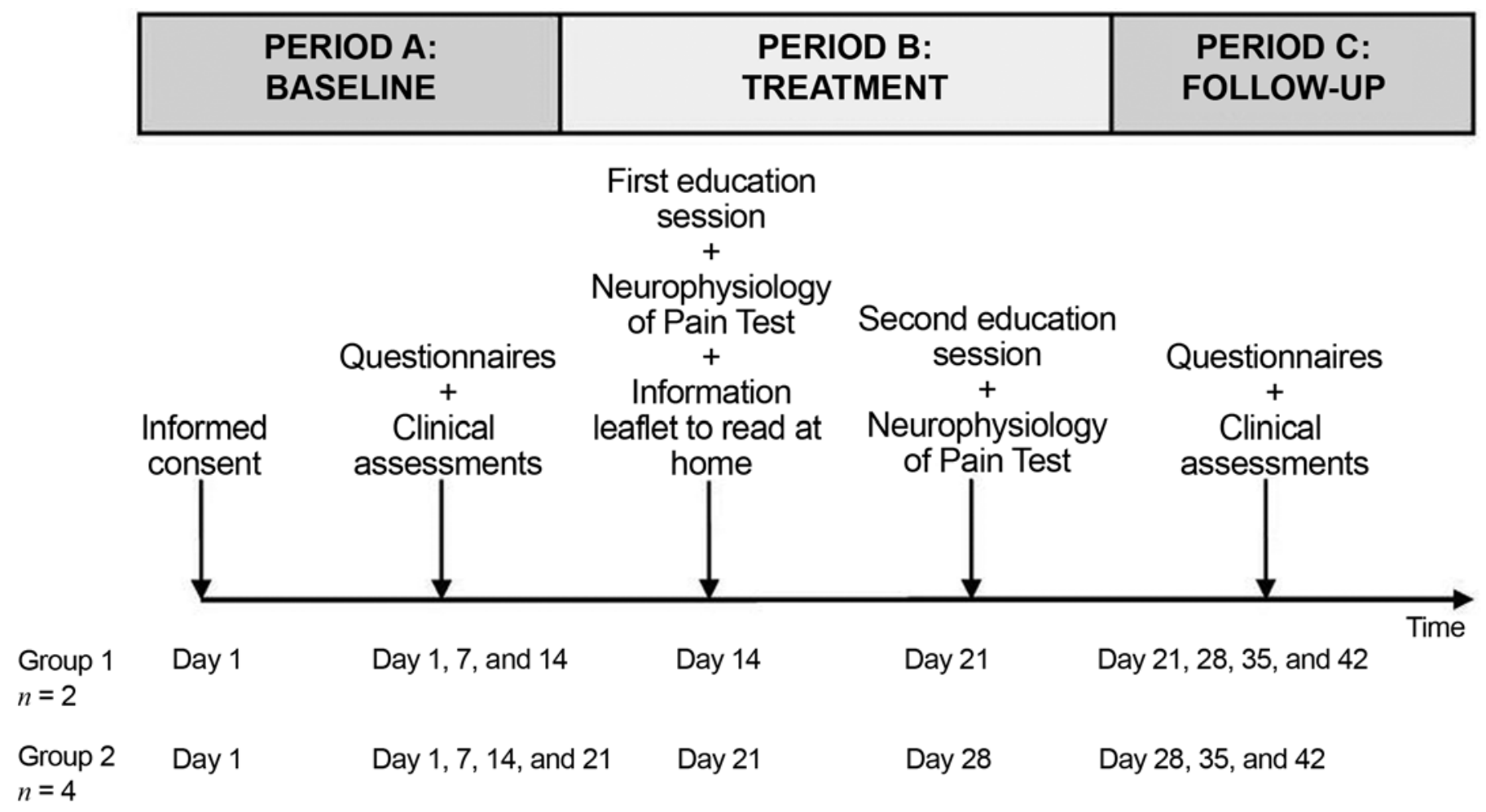

Figure 1.

Study protocol. Questionnaires: Neck Disability Index, Whiplash Associated Disorders Symptom List, Pain Catastrophizing Scale, Pain Coping Inventory, and Tampa Scale for Kinesiophobia. Clinical assessments: Neck Extension Test, Brachial Plexus Provocation Test, and pain pressure thresholds.

into two groups and blinded the assessor to the group allocation. Both groups received the same treatment and underwent the same measurements but differed in the sequence of events that took place during the study period. Hence, we blinded the assessor to the exact moment at which the intervention took place. The first group consisted of two patients who received their baseline measurements (period A) on days 1, 7, and 14. On day 14, they received the first treatment session (period B). The second session was given on day 21 followed by the first posttreatment measurements. The follow-up measurements (period C) were given on days 28, 35, and 42. The second group consisted of four patients who received the baseline measurements (period A) on days $1,7,14$, and 21, followed by the treatment on days 21 and 28, and finally the follow-up (period C) on days 28, 35, and 42. We subjected the first group to three preassessments and four postassessments, while the second group underwent four preassessments and three postassessments as presented in Figure 1.

\section{Measurements and Questionnaires}

We chose the NDI and the pain pressure thresholds (PPTs) as the primary outcome measures. The NDI was developed in 1991 as a modification of the Oswestry Back Pain Index and was the first instrument designed to assess self-rated disability in patients with neck pain [3940]. The NDI is scored from 0 (good function) to 50 (poor function), and the percentage of disability can be obtained when the score is multiplied by two. The NDI is a valid and reliable instrument sensitive to measure changes within a population of patients with neck pain [39-40].

We measured PPTs bilaterally with an analog Fisher algometer (Force Dial model FDK 40 Push Pull Force Gage, Wagner Instruments; Greenwich, Connecticut) in the skin web between thumb and index finger [41], at the proximal third of the calf, and at the upper trapezius muscle (pars descendens) midway between cervical 7 and the tip of the acromion [42]. We assessed these sites in random order. We gradually increased the force at a rate of 
$1 \mathrm{~kg} / \mathrm{m}^{2} / \mathrm{s}$ [43]. We defined PPT as the point at which the pressure sensation turned to pain [8]. We determined the PPT as the mean of the two last values out of three consecutive measurements (10 $\mathrm{s}$ in between), since this procedure has found to be reliable in nondisabled controls [43]. Algometry provides a reliable and valid measure of PPTs [44].

The WAD Symptom List is a self-reported measure for assessing symptom severity in patients with WAD. The questionnaire is composed of the most reported WAD symptoms in the literature and some autonomic symptoms [25,45-46]. Every symptom is presented by a visual analog scale (VAS) $(100 \mathrm{~mm})$, a method that is known for its validity and reliability [47]. Previously, our research group found a good internal consistency (Cronbach $\alpha=0.92$ ) for the WAD symptom list (unpublished data).

The TSK is a 17-item questionnaire that measures the fear of (re)injury due to movement [48]. Items are scored on a 4-point Likert scale, and a total score is calculated (1-4 for each item) after inversion of the individual scores of items $4,8,12$, and 16 . The total scores for the TSK range from 17 to 68 , with scores of $\leq 37$ suggesting low fear of movement and scores $>37$ indicating high fear of movement [49-50]. The TSK-Dutch version used in this study is a reliable and valid measure [12,50-52].

We used the PCS-Dutch version (PCS-DV) to measure catastrophic thinking about pain [51,53]. This selfreported questionnaire consists of 13 items describing different thoughts and feelings that individuals may experience when experiencing pain. Items are scored on a 5-point scale, and one general score can be obtained for the degree of catastrophic thoughts about pain by adding up all individual item scores. This general score can be subdivided into three subscales: Helplessness, Magnification, and Rumination. Higher scores correspond to more severe catastrophic thoughts about pain. The psychometric properties of the PCS-DV are well established [51,54-55].

The PCI consists of six scales (33 items) measuring cognitive and behavioral pain-coping strategies that represent two higher order pain coping dimensions: active (distraction, transformation, and reducing demands) and passive (resting, retreating, and worrying) [56]. Patients are asked to indicate how often they apply a certain strategy when dealing with pain on 4-point Likert scale ranging from 1 (hardly ever) to 4 (very often). Internal consistency, test-retest reliability, validity, and sensitivity are reported as good in different patient populations [56-57].
The Neck Extension Test is used to diagnose sensory disturbances in patients with whiplash and is able to discriminate between subjects with symptoms after a whiplash injury and subjects without head or neck complaints [58-59]. During the test, patients sit looking straight forward and are asked to move their head backward as far as possible resulting in cervical extension. The patient's willingness to perform the movement is registered and the degree of pain experienced during the test performance is measured using a VAS. When there is a problem with the motor control of the movement, patients are frequently anxious about moving their head toward extension [60]. Then, the patient is asked to make the same movement, placing their index finger on a selfchosen cervical segment. When the involved segment has impaired motor control, then the cervical spine will extend better and the movement will be less or not at all painful during this test situation [60]. Therefore, patients are asked which movement felt better and pain is measured using a VAS.

The BPPT is performed with the patient lying faceup. First, a gentle shoulder depression is carried out, followed by a glenohumeral abduction and external rotation, wrist and finger extension, and elbow extension [11]. The elbow extension is stopped when the patient reports that the test is unpleasant or painful. The obtained range of elbow extension during the BPPT is measured using a standard goniometer aligned along the midhumeral shaft, medial epicondyle, and ulnar styloid [61-62]. If no pain is experienced, elbow extension is continued to the normal end of range. At the completion of the test, the subjects are asked to rate pain on a VAS [11]. According to Coppieters et al., pain provocation during neurodynamic testing is a stable phenomenon and the range of elbow extension corresponding with the moment of "pain onset" and "submaximal pain" may be measured reliably, both in laboratory and clinical conditions [63]. We performed the test three times on each arm and calculated an average for each side.

\section{Intervention}

The intervention consisted of two educational sessions and an information leaflet about the neurophysiology of pain. We used the Neurophysiology of Pain Test (patient version) to tailor the second educational secession. All subjects participated in two one-on-one educational sessions about the neurophysiology of pain. Each session lasted about 30 minutes. The intervention was delivered 
by a therapist with a bachelor's degree in physiotherapy, who received training from two therapists with master's degrees in physiotherapy and experience in providing pain physiology education. The therapist who conducted the educational sessions was blinded to the results of the measurements and questionnaires. The content and pictures of the educational sessions were based on the book Explain Pain [64-66]. The education covered the physiology of the nervous system in general and of the pain system in particular. The information was presented in detail using pictures, examples, and metaphors. We started the sessions by questioning the patient on their illness perceptions and pain cognitions. The therapist used this information to individually tailor the educational session. Topics addressed during the educational sessions included the characteristics of acute versus chronic pain; the purpose of acute pain; how acute pain originates in the nervous system (nociceptors, ion gates, neurons, action potential, nociception, peripheral sensitization, synapses, synaptic gap, inhibitory/excitatory chemicals, spinal cord, descending/ascending pain pathways, brain role, pain memory, and pain perception); how pain becomes chronic (plasticity of the nervous system, modulation, modification, central sensitization, pain neuromatrix theory); and potential sustaining factors of central sensitization like emotions, stress, pain cognitions, and pain behavior. We developed the educational session in line with the content of the Neurophysiology of Pain Test in such a way that after having received the education, patients should be able to answer all questions of the test correctly. We presented the educational information verbally (explanation by the therapist) and visually (summaries, pictures, and diagrams on computer and paper). Patients could ask questions during the sessions, and we used their input to individualize the information. After the first session, we asked patients to fill out the Neurophysiology of Pain Test, a questionnaire to assess their knowledge on pain neurophysiology [65]. This is a valid and reliable questionnaire with 19 posings concerning nociception and the modulation of nociception that need to be answered with "true," "false," or "undecided" [66]. A score can be calculated by adding the correct answers, for a total possible maximum score of 19 . We used the Neurophysiology of Pain Test as a part of the intervention to control which topics needed additional explanation during the second session. Patients also received an information leaflet about the neurophysiology of pain and were asked to read it carefully at home. Patients with chronic
WAD often report impairments in attention and concentration and could be less focused on some aspects of the verbal education. Therefore, additional written information that can be read afterwards is a valuable and essential part of the intervention. During the second session, the therapist answered and explained additional questions that arose after reading the information leaflet. Based on incorrect answers scored on the Neurophysiology of Pain Test, the therapist selected those items and explained them once again and, if necessary, in more detail. Afterwards, we asked patients to fill out the Neurophysiology of Pain Test once again, to examine whether they understood all the information provided.

\section{Statistical Analysis}

We analyzed all data using SPSS version 16.0 for Windows (SPSS Inc; Chicago, Illinois). We calculated appropriate descriptive statistics and, to account for missing data (see the "Results" section), used the "last observation carried forward" method for the intention-to-treat analysis. We compared baseline scores between the seven different assessment points using the Wilcoxon signed ranks test to assess the natural variability of the symptoms. For every variable, we calculated an average score from the baseline measurements and another from the follow-up measurements. We examined the treatment effect by comparing the average baseline score with the average follow-up scores. Although we calculated one average baseline score and one average follow-up score for statistical comparison, Figures 2 through 8 show the evolution of the scores over time.

Using a Wilcoxon signed ranks test, we compared average test scores on baseline variables with average test scores on posttreatment variables to establish the therapy effect. We set the significance level at 0.05 . We calculated effect sizes (ESs) as Cohen's $d$, with $d$ defined as the difference between the two means divided by the pooled standard deviation for those means. A $d$-value of 0.20 is described as small, 0.50 as medium (moderate), and 0.80 as large [67]. Table 1 presents $d$-values translated into percentiles. For example, for an ES of 0.6, the value of 73 percent indicates that the average person in the experimental group would score higher than 73 percent of the control group, assuming that the two were initially equivalent. 


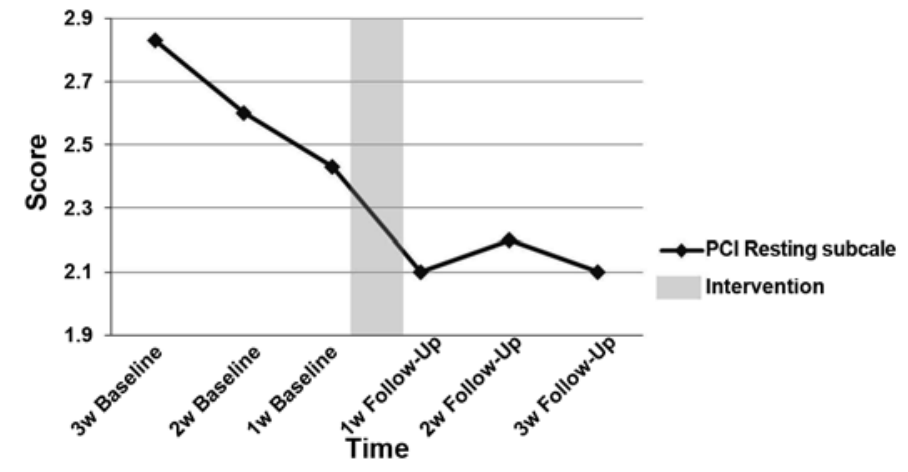

Figure 2.

Evolution of mean Pain Coping Inventory (PCI) Resting subscale scores over time in six patients with chronic whiplash associated disorders. Baseline assessments at 3, 2, and 1 week before intervention; follow-up assessments 1, 2, and 3 weeks after intervention.

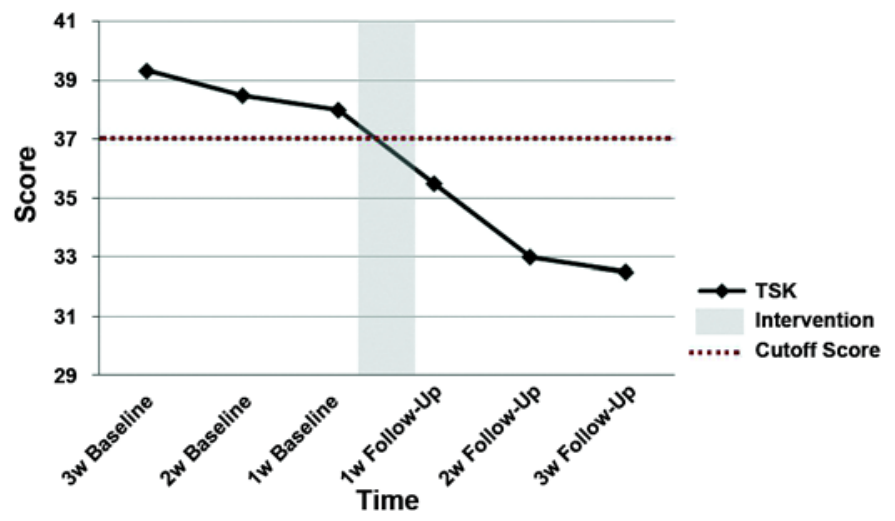

Figure 3.

Evolution of mean Tampa Scale for Kinesiophobia (TSK) scores over time in six patients with chronic whiplash associated disorders. Baseline assessments at 3, 2, and 1 week before intervention; follow-up assessments 1, 2, and 3 weeks after intervention.

\section{RESULTS}

Six patients with WAD grades I to II according to QTF-WAD guidelines participated in the study. The mean time since onset of pain was $50.3 \pm 28.2$ months. The group consisted of 5 females and 1 male, and the mean age was $35.7 \pm 7.3$ years. All patients were Caucasian. One patient reported the use of lidocaine patches (analgesic) and one patient occasionally used tetrazepam (anxiolytic and muscle relaxant). Table 2 presents detailed information about each patient.

We found no significant differences between the different baseline measurements that we collected weekly;

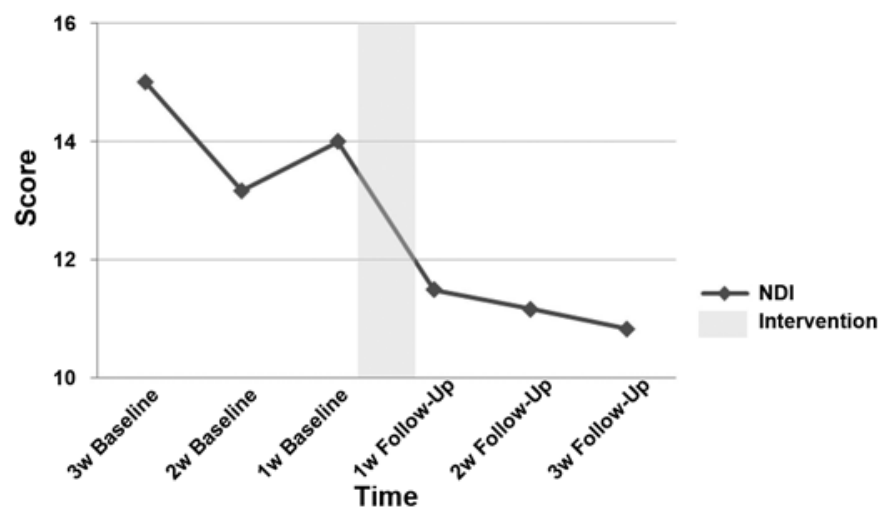

Figure 4.

Evolution of mean Neck Disability Index (NDI) scores over time in six patients with chronic whiplash associated disorders. Baseline assessments at 3, 2, and 1 week before intervention; follow-up assessments 1,2 , and 3 weeks after intervention.

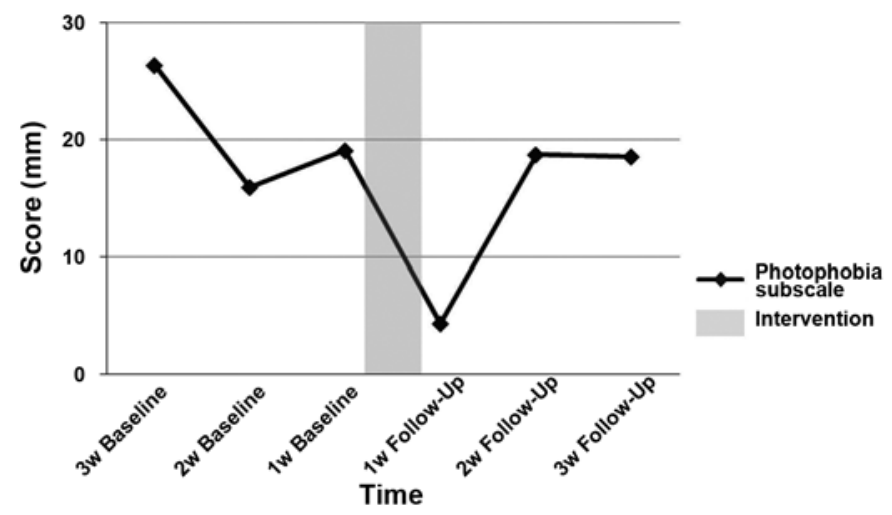

Figure 5.

Evolution of mean Whiplash Associated Disorders (WAD) Symptom List Photophobia subscale scores by visual analog scale over time in six patients with chronic WAD. Baseline assessments at 3, 2, and 1 week before intervention; follow-up assessments 1,2 , and 3 weeks after intervention.

thus, we calculated an average score for every variable. We also calculated an average score for every variable for the follow-up measurements. The Wilcoxon signed ranks test showed some significant changes between the average test scores before and after the intervention (Table 1).

After patients received education about the neurophysiology of pain, we found some significant changes in the primary outcome measures. A significant decrease in average NDI scores was established $(p=0.046)$, and five out of six patients showed an average improvement of 17.7 percent on the NDI. After the education session, the percentage of neck disability (NDI) reduced from 28.3 to 


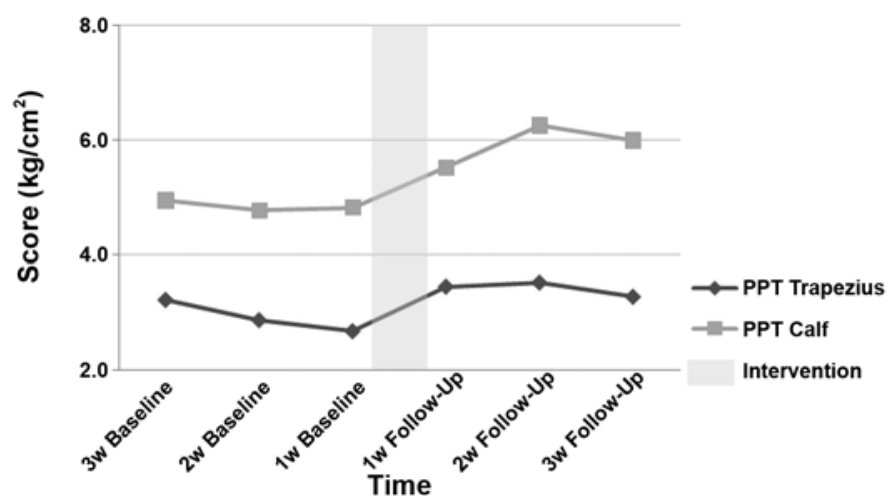

Figure 6.

Evolution of mean pain pressure threshold (PPT) scores over time in six patients with chronic whiplash associated disorders. Baseline assessments at 3, 2, and 1 week before intervention; follow-up assessments 1,2 , and 3 weeks after intervention.

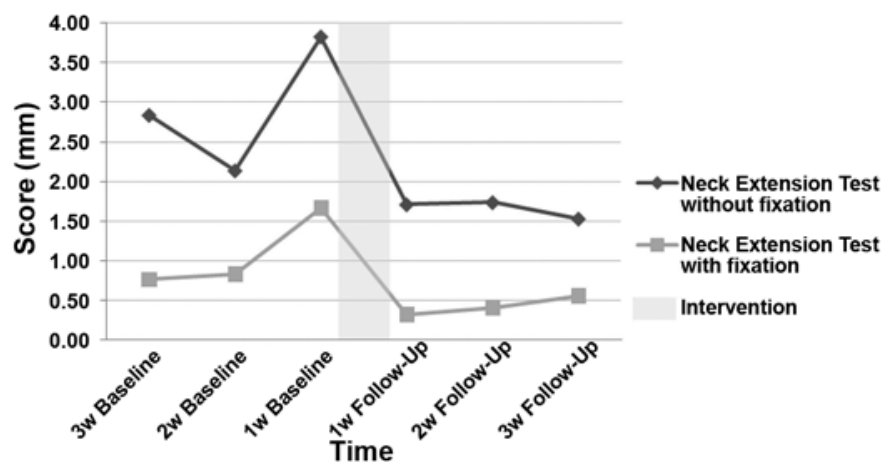

Figure 7.

Evolution of mean Neck Extension Test scores by visual analog scale over time in five patients with chronic whiplash associated disorders. Baseline assessments at 3, 2, and 1 week before intervention; followup assessments 1, 2, and 3 weeks after intervention.

22.7 percent. PPTs measured at the trapezius muscle $(p=$ $0.03)$ and the calf $(p=0.04)$ improved significantly after the intervention. While all patients showed improved PPTs measured near the neck (33.3\% improvement), five out of six patients showed improved PPTs measured at the calf (25.5\% improvement).

After the intervention, we found a decrease in every PCI subscale score regarding passive coping. The Resting subscale significantly decreased ( $p=0.03, d=1.29$ ) in all patients with WAD, with a change in scores of 18.3 percent. While in five out of six subjects, the mean scores on the Retreating and Worrying subscales decreased by 8.1 and 8.7 percent, respectively, the changes were not

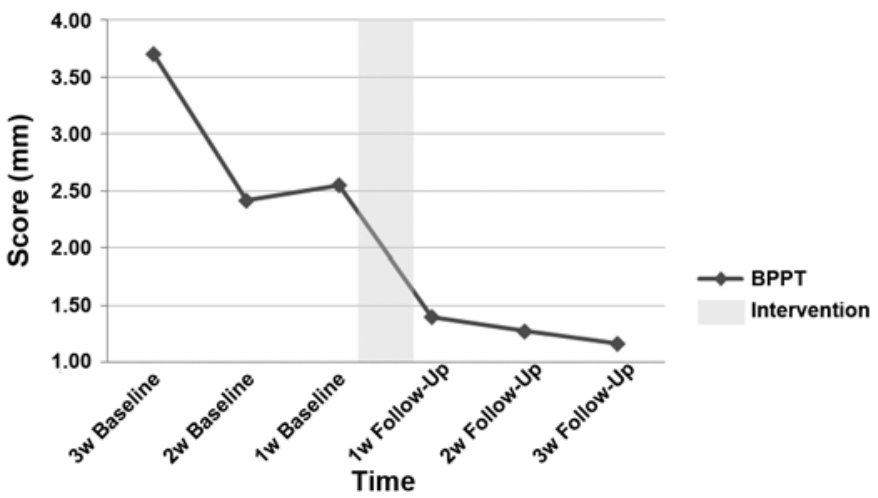

Figure 8.

Evolution of mean Brachial Plexus Provocation Test (BPPT) scores by visual analog scale over time in six patients with chronic whiplash associated disorders. Baseline assessments at 3, 2, and 1 week before intervention; follow-up assessments 1,2 , and 3 weeks after intervention.

significant (Retreating subscale: $p=0.08, d=0.25$; Worrying subscale: $p=0.09, d=0.31$ ). We found no significant changes for the PCI subscales regarding active coping and for the PCS. We did, however, find a significant decrease in the score on the TSK ( $p=0.03, d=0.82$ ); all patients with WAD showed an average improvement on the TSK of 13.8 percent. Using the WAD Symptom List, we observed a significant reduction in photophobia $(p=$ $0.04, d=0.34$ ).

One patient from group 1 did not attend the physical examinations performed on day 35 . We replaced the missing values using the last observation carried forward method. After patients received the education intervention, pain scores during the BPPT reduced significantly ( $p=0.04, d=1.45$ ) from $31.15 \mathrm{~mm}$ to $12.47 \mathrm{~mm}$. During the Neck Extension Test, patients' willingness to perform the movement was registered to indicate whether there was a problem with their motor control, which often translated to anxiousness to perform the movement. This was the case for one patient who refused to perform the Neck Extension Test during the examinations in fear of pain provocation. At baseline, patients scored significantly lower $(p=0.04)$ on the VAS during performance of the Neck Extension Test when they were able to fixate a selfchosen cervical segment. At the follow-up measurements, the difference was no longer found to be significant ( $p=$ 0.07). On the question "Could you perform the movement better during the test with or without fixation?" all patients replied that the test with fixation helped them to perform the cervical extension movement better. This was 
Table 1.

Results of questionnaires and clinical assessments analyzed with Wilcoxon signed ranks test in six patients with chronic whiplash associated disorders (WAD).

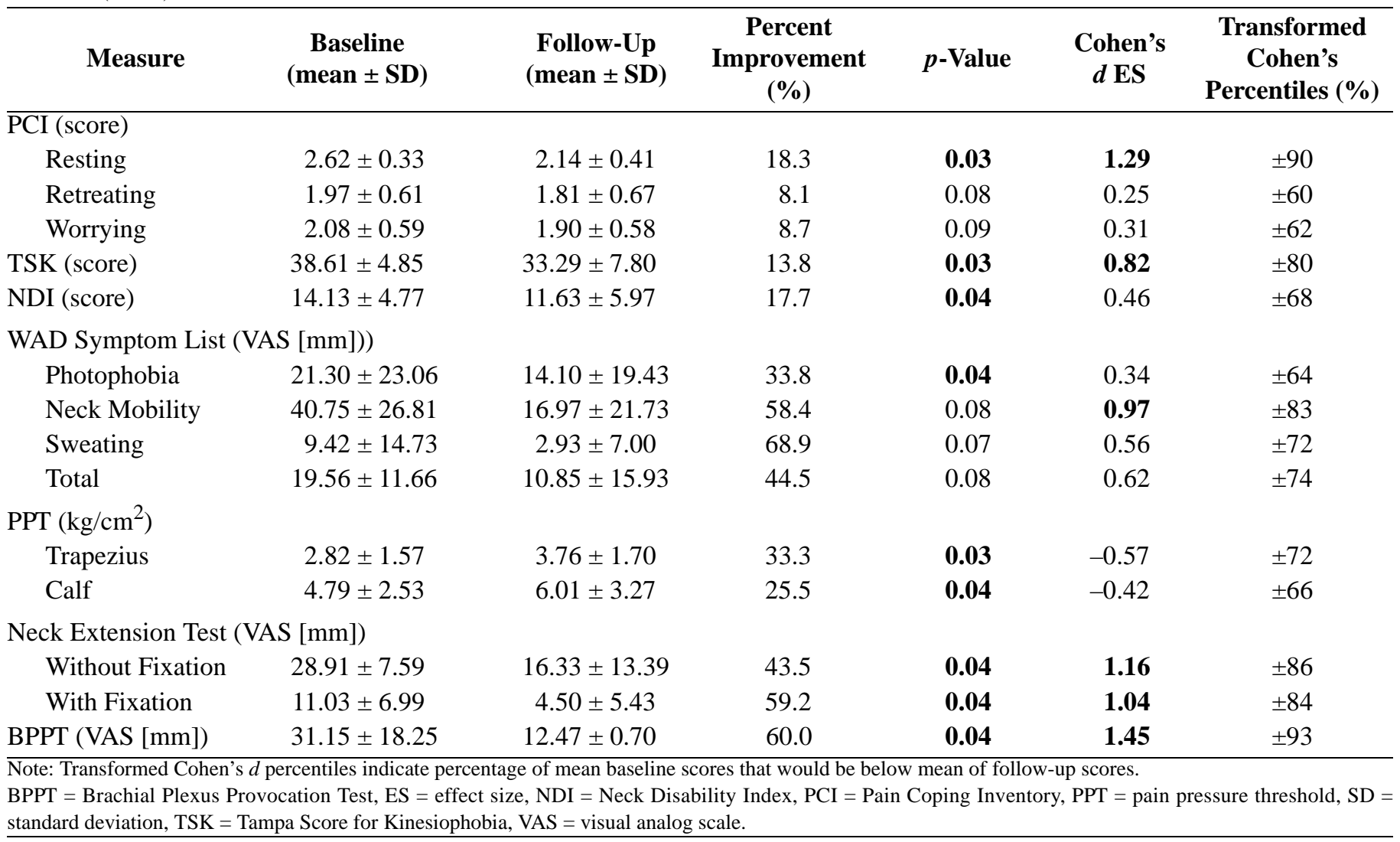

Table 2.

Demographic characteristics of patients with whiplash associated disorders.

\begin{tabular}{|c|c|c|c|c|c|c|c|}
\hline Patient & Sex & Age (yr) & $\begin{array}{c}\text { Time Since } \\
\text { Onset of } \\
\text { Complaints } \\
\text { (mo) }\end{array}$ & $\begin{array}{l}\text { Marital } \\
\text { Status }\end{array}$ & $\begin{array}{c}\text { Parental } \\
\text { Status (No. } \\
\text { of children) }\end{array}$ & $\begin{array}{l}\text { Analgesic } \\
\text { Use }\end{array}$ & $\begin{array}{c}\text { Antidepressant } \\
\text { Use }\end{array}$ \\
\hline 1 & $\mathrm{M}$ & 49 & 12 & Married & 4 & No & No \\
\hline 2 & $\mathrm{~F}$ & 29 & 46 & Not married & 0 & No & Yes \\
\hline 3 & $\mathrm{~F}$ & 35 & 72 & Not married & 0 & No & No \\
\hline 5 & $\mathrm{~F}$ & 31 & 64 & Not married & 0 & No & No \\
\hline 6 & $\mathrm{~F}$ & 32 & 84 & Not married & 0 & Yes & No \\
\hline
\end{tabular}

the case for both the baseline and follow-up measurements. Comparing the Neck Extension Test before and after the intervention, we recorded a significant reduction of 43.5 percent on the VAS for the test without fixation ( $p=$ $0.04, d=1.16$ ) and 59.2 percent for the test with fixation $(p=0.04, d=1.04)$.

\section{DISCUSSION}

These data from a single-case study on six patients with chronic WAD suggest that pain physiology education is accompanied by improvements in pain cognitions, pain thresholds, and pain-free movement performance. 
Because there were no significant changes between the different assessment scores that were repeated weekly during the baseline period, we can accept that these improvements were due to the intervention.

During the baseline period, the average score on the TSK indicated high fear of movement in all patients with WAD. Throughout the education, we explained the positive effect of movement on the healing process of damaged tissues and informed patients that movement would not per se cause (re)injury (even if they are in pain). During the follow-up period, we observed a significant decrease in kinesiophobia and, using the cutoff score of 37, identified low fear of movement in all participants. In addition, resting was significantly less used in response to pain, and while it was not found significant, patients reported using fewer passive coping strategies such as worrying and retreating.

Hypervigilance, catastrophizing, and avoidance behavior are important psychosocial factors of cognitive emotional sensitization. Descending facilitatory pathways have been identified connecting the brain stem with the spinal cord. Behavioral evidence shows that forebrain centers, responsible for emotional and cognitive control, are capable of exerting powerful clinically significant influences on various nuclei of the brain stem [68]. In addition, the limbic system - a group of structures in the brain involved in emotions, moods, and regulation of emotional reactions-is neurophysiologically connected to nuclei in the brain stem from which the pain facilitatory pathways depart [68]. Consequently, negative emotions, thoughts, attention, stress, etc., can modulate the activity in the descending pathways, facilitating pain and resulting in cognitive emotional sensitization [68]. In cases of hypervigilance, catastrophizing, or avoidance behavior, intensive education about the exact nature of chronic whiplash pain is likely to facilitate effective rehabilitation. McClune et al. developed an evidence-based educational booklet, The Whiplash Book [69-70]. The content emphasizes the positive prognosis of whiplash injuries and promotes activity [69]. Patients with acute WAD showed a substantial improvement in beliefs after reading the book. In contrast, patients with WAD attending a private practice for manipulation showed only a small change in beliefs, and the authors argued that this may have been due to the chronicity of their symptoms [70]. Changing inappropriate pain beliefs should be the initial phase of rehabilitation in those with chronic WAD. If not, poor understanding of pain may lead to the acqui- sition of maladaptive attitudes, cognitions, and behavior in relation to pain and consequently poor compliance to any active treatment.

After reconceptualizing pain during the educational sessions, patients' improvements in pain behavior during the follow-up period were accompanied by a decrease in symptoms. We established a trend for a decrease in overall symptom severity (the total score on the WAD Symptom List) with a Cohen's $d$ ES of 0.62 (transformed Cohen's $d=74 \%$ ). Patients reported less sweating (transformed Cohen's $d=72 \%$ ) and photophobia (transformed Cohen's $d=64 \%$ ). Sweating and photophobia are symptoms that indicate the presence of central sensitization. It seems plausible that improving pain beliefs and behavior is important, not only for enabling proper functioning of the central pain-inhibitory pathways, but also for improving movement performance. Inappropriate cognitions appear closely related to movement performance [27,32]. Patients reported a trend toward improvement in neck mobility on the WAD Symptom List and a significant decrease on self-rated disability (NDI). Neck disability experienced by patients decreased from 28.26 to 22.72 percent. These results are comparable to the findings of Moseley [30], although that study used four educational sessions of 1 hour each in combination with physiotherapy to reduce disability in patients with chronic low back pain. The present study achieved similar responses in patients with chronic WAD using only two educational sessions of 30 minutes each. An educational session of 30 minutes would be more suitable for application to clinical practice. Not only are treatment sessions with a physical therapist restricted in time, patients with chronic WAD additionally often experience attention and concentration difficulties.

Using the Neck Extension Test, we established impairment in cervical motor control at baseline. After the intervention, we could detect no significant impairment and moreover, patients experienced significantly less pain during cervical movement performance. We observed the same during the BPPT, where we established an improvement in pain-free movement of 60 percent. We found a large ES ranking in the ninety-third Cohen's percentile. PPTs measured near the neck and the calf increased significantly by 33.2 and 25.5 percent, respectively. By altering pain cognitions, such as pain coping and avoidance behavior, it could be possible that patients are more exposed to activity that in turn leads to increased or altered performance [13,71]. In the longer 
term, this could result in increased PPTs and pain tolerance. The combination of self-reported measures and clinical assessments is a strength of this study. For future research it would be useful to examine whether pain education improves cervical mobility during performance of the Neck Extension Test as well.

Education about pain neurophysiology is one aspect of chronic pain rehabilitation, and it would be useful to further examine its effect in combination with other therapies. Although it seems interesting to examine the effect of combined treatment, we first wished to examine whether education on pain neurophysiology has any potential for patients with chronic WAD. Although the present pilot study was small, it is remarkable that we observed some important significant changes and ESs. Besides, the single-case study design is a research design that has proven its usefulness in the behavioral sciences. In medical science it is often used to systematically evaluate new treatments for specific (usually chronic) patient populations. The baseline period typically consists of several baseline assessments that account for the natural variability of the patients' health status. If this natural variability of the chronic patient is suddenly "disturbed" during the intervention period, the change might be attributed to the intervention. Hence, the single-case study design can be used to examine the feasibility of a new treatment for a particular population in preparation of a large randomized, controlled clinical trial. Caution should be taken with generalizing the study findings. The study findings are solely applicable to people with WAD grades I to II. Currently, data addressing the applicability of pain physiology education in patients with chronic WAD grades III to IV are currently unavailable. In addition, we used a small sample size and the effects of education are dependent on not only the format, the content, and the patient, but also the practitioner providing the education. The attitude of the healthcare provider is crucial in educating patients [72]. Although the current results need to be verified in a randomized clinical trial, the present study suggests that education about the neurophysiology of pain is able to increase PPTs and improve pain behavior and pain-free movement performance.

\section{CONCLUSIONS}

Chronic WAD is a debilitating and costly condition, and treatment remains challenging for clinicians, including rehabilitation specialists and physiotherapists. Because very few trials have evaluated conservative interventions for patients with chronic WAD, clinical studies examining the effectiveness of conservative treatment strategies are required. Changing inappropriate pain beliefs should be the initial phase of rehabilitation in those with chronic WAD. If not, poor understanding of pain may lead to the acquisition of maladaptive attitudes, cognitions, and behavior in relation to pain and subsequent poor compliance to any active treatment. The results of this pilot study suggest that rehabilitation specialists and physical therapists are able to influence negative thoughts and pain behavior by educating patients with chronic WAD about the neurophysiology of pain. The improvement in pain behavior resulted in improved neck disability and increased pain-free movement performance and pain thresholds.

\section{ACKNOWLEDGMENTS}

\section{Author Contributions:}

Study concept and design: J. Nijs.

Acquisition of data: N. Van den Keybus, J. Craps.

Analysis and interpretation of data: J. Van Oosterwijck.

Drafting of manuscript: J. Van Oosterwijck.

Critical revision of manuscript for important intellectual content:

M. Meeus, J. Nijs, L. Paul.

Statistical analysis: S. Truijen, J. Van Oosterwijck.

Study supervision: J. Nijs, J. Van Oosterwijck.

Financial Disclosures: The authors have declared that no competing interests exist.

Funding/Support: This material was based on work supported by the Faculty of Physical Education \& Physiotherapy, Vrije Universiteit Brussel (PhD grant to Ms. Van Oosterwijck, Onderzoeksraad project 1596). Dr. Meeus is a postdoctoral research fellow of the Fund for Scientific Research Flanders.

Additional Contributions: The authors are grateful to the Department of Physical Medicine, University Hospital Antwerp, for providing study facilities and study subjects.

Institutional Review: The Ethics Committee of the University Hospital of Antwerp approved this study. Subjects signed an informed consent form.

Participant Follow-Up: The authors plan to inform participants of the publication of this study.

\section{REFERENCES}

1. Spitzer WO, Skovron ML, Salmi LR, Cassidy JD, Duranceau J, Suissa S, Zeiss E. Scientific monograph of the Quebec Task Force on whiplash-associated disorders: Redefining 
“whiplash” and its management. Spine. 1995;20(8 Suppl): 1S-73S. [PMID: 7604354]

2. Barnsley L, Lord S, Bogduk N. Whiplash injury. Pain. 1994;58(3):283-307. [PMID: 7838578]

3. Lovell ME, Galasko CS. Whiplash disorders-A review. Injury. 2002;33(2):97-101. [PMID: 11890909] DOI:10.1016/S0020-1383(01)00111-5

4. Rodriquez AA, Barr KP, Burns SP. Whiplash: Pathophysiology, diagnosis, treatment, and prognosis. Muscle Nerve. 2004;29(6):768-81. [PMID: 15170609] DOI:10.1002/mus.20060

5. Stovner LJ. The nosologic status of the whiplash syndrome: A critical review based on a methodological approach. Spine. 1996;21(23):2735-46. [PMID: 8979319$]$ DOI:10.1097/00007632-199612010-00006

6. Lee J, Giles K, Drummond PD. Psychological disturbances and an exaggerated response to pain in patients with whiplash injury. J Psychosom Res. 1993;37(2):105-10. [PMID: 843986] DOI:10.1016/0022-3999(93)90076-R

7. Sterling M, Jull G, Vicenzino B, Kenardy J, Darnell R. Physical and psychological factors predict outcome following whiplash injury. Pain. 2005;114(1-2):141-48. [PMID: 15733639]

8. Banic B, Petersen-Felix S, Andersen OK, Radanov BP, Villiger PM, Arendt-Nielsen L, Curatolo M. Evidence for spinal cord hypersensitivity in chronic pain after whiplash injury and in fibromyalgia. Pain. 2004;107(1-2):7-15. [PMID: 14715383]

9. Herren-Gerber R, Weiss S, Arendt-Nielsen L, PetersenFelix S, Di Stefano G, Radanov BP, Curatolo M. Modulation of central hypersensitivity by nociceptive input in chronic pain after whiplash injury. Pain Med. 2004;5(4): 366-76. [PMIDL 15563322] DOI:10.1111/j.1526-4637.2004.04055.x

10. Sterling M, Jull G, Vicenzino B, Kenardy J. Sensory hypersensitivity occurs soon after whiplash injury and is associated with poor recovery. Pain. 2003;104(3):509-17. [PMID: 12927623]

11. Sterling M, Treleaven J, Edwards S, Jull G. Pressure pain thresholds in chronic whiplash associated disorder: Further evidence of altered central pain processing. J Musculoskel Pain. 2002;10(3):69-81. DOI:10.1300/J094v10n03 05

12. Nederhand MJ, IJzerman MJ, Hermens HJ, Turk DC, Zilvold G. Predictive value of fear avoidance in developing chronic neck pain disability: Consequences for clinical decision making. Arch Phys Med Rehabil. 2004;85(3): 496-501. [PMID: 15031840] DOI:10.1016/j.apmr.2003.06.019

13. Nieto R, Miró J, Huguet A. The fear avoidance model in whiplash injuries. Eur J Pain. 2009;13(5):518-23.

\section{[PMID: 18640860]}

DOI:10.1016/j.ejpain.2008.06.005

14. Sterling M, Jull G, Kenardy J. Physical and psychological factors maintain long-term predictive capacity postwhiplash injury. Pain. 2006;122(1-2):102-8.

[PMID: 16527397]

15. Stewart MJ, Maher CG, Refshauge KM, Herbert RD, Bogduk N, Nicholas M. Randomized controlled trial of exercise for chronic whiplash-associated disorders. Pain. 2007;128(1-2):59-68. [PMID: 17029788]

16. Stewart MJ. Treatment of chronic whiplash [dissertation]. [Sydney, Australia]: University of Sydney; 2005.

17. Verhagen AP, Scholten-Peeters GG, Van Wijngaarden S, De Bie RA, Bierma-Zeinstra SM. Conservative treatments for whiplash. Cochrane Database Syst Rev. 2007;2:CD003338. [PMID: 17443525]

18. Holm LW, Carroll LJ, Cassidy JD, Skillgate E, Ahlbom A. Expectations for recovery important in the prognosis of whiplash injuries. PLoS Med. 2008;5(5):e105.

[PMID: 18479182]

DOI:10.1371/journal.pmed.0050105

19. Oliveira A, Gevirtz R, Hubbard D. A psycho-educational video used in the emergency department provides effective treatment for whiplash injuries. Spine. 2006;31(15):1652-57. [PMID: 16816758]

DOI:10.1097/01.brs.0000224172.45828.e3

20. Vendrig AA, Van Akkerveeken PF, McWhorter KR. Results of a multimodal treatment program for patients with chronic symptoms after a whiplash injury of the neck. Spine. 2000;25(2):238-44. [PMID: 10685489]

DOI:10.1097/00007632-200001150-00016

21. Berglund A, Bodin L, Jensen I, Wiklund A, Alfredsson L. The influence of prognostic factors on neck pain intensity, disability, anxiety and depression over a 2-year period in subjects with acute whiplash injury. Pain. 2006;125(3): 244-56. [PMID: 16806708]

22. Söderlund A, Lindberg P. Cognitive behavioural components in physiotherapy management of chronic whiplash associated disorders (WAD) - A randomised group study. G Ital Med Lav Ergon. 2007;29(1 Suppl A):A5-11. [PMID: 17650736]

23. Börsbo B, Peolsson M, Gerdle B. Catastrophizing, depression, and pain: Correlation with and influence on quality of life and health-A study of chronic whiplash-associated disorders. J Rehabil Med. 2008;40(7):562-69.

[PMID: 18758674] DOI:10.2340/16501977-0207

24. Kamper SJ, Rebbeck TJ, Maher CG, McAuley JH, Sterling M. Course and prognostic factors of whiplash: A systematic review and meta-analysis. Pain. 2008;138(3):617-29. [PMID: 18407412] 
25. Söderlund A, Lindberg P. Whiplash-associated disordersPredicting disability from a process-oriented perspective of coping. Clin Rehabil. 2003;17(1):101-7. [PMID: 12617385] DOI:10.1191/0269215503cr566oa

26. Jackson T, Pope L, Nagasaka T, Fritch A, Iezzi T, Chen H. The impact of threatening information about pain on coping and pain tolerance. Br J Health Psychol. 2005;10(Pt 3): 441-51. [PMID: 16238858] DOI:10.1348/135910705X27587

27. Moseley GL. Evidence for a direct relationship between cognitive and physical change during an education intervention in people with chronic low back pain. Eur J Pain. 2004;8(1):39-45. [PMID: 14690673] DOI:10.1016/S1090-3801(03)00063-6

28. Moseley GL. A pain neuromatrix approach to patients with chronic pain. Man Ther. 2003;8(3):130-40. [PMID: 12909433] DOI:10.1016/S1356-689X(03)00051-1

29. Moseley GL. Joining forces-Combining cognition-targeted motor control training with group or individual pain physiology education: A successful treatment for chronic low back pain. J Man Manip Ther. 2003;11(2):88-94. DOI:10.1179/106698103790826383

30. Moseley GL. Combined physiotherapy and education is efficacious for chronic low back pain. Austr J Physiother. 2002;48(4):297-302. [PMID: 12443524]

31. Moseley GL, Nicholas MK, Hodges PW. A randomized controlled trial of intensive neurophysiology education in chronic low back pain. Clin J Pain. 2004;20(5):324-30. [PMID: 15322439] DOI:10.1097/00002508-200409000-00007

32. Moseley GL. Widespread brain activity during an abdominal task markedly reduced after pain physiology education: fMRI evaluation of a single patient with chronic low back pain. Austr J Physiother. 2005;51(1):49-52.

[PMID: 15748125]

DOI:10.1016/j.apmr.2010.04.020

33. Meeus M, Nijs J, Van Oosterwijck J, Van Alsenoy V, Truijen S. Pain physiology education improves pain beliefs in patients with chronic fatigue syndrome compared with pacing and self-management education: A double-blind randomized controlled trial. Arch Phys Med Rehabil. 2010; 91(8):1153-59. [PMID: 20684894]

34. Nijs J, Van Oosterwijck J, De Hertogh W. Rehabilitation of chronic whiplash: Treatment of cervical dysfunctions or chronic pain syndrome. Clin Rheumatol. 2009;28(3):243-51. [PMID: 19160000]

DOI:10.1007/s10067-008-1083-X

35. Borchgrevink GE, Smevik O, Nordby A, Rinck PA, Stiles TC, Lereim I. MR imaging and radiography of patients with cervical hyperextension-flexion injuries after car accidents. Acta Radiol. 1995;36(4):425-28. [PMID: 7619624$]$
36. Deans GT, Magalliard JN, Kerr M, Rutherford WH. Neck sprain: A major cause of disability following car accidents. Injury. 1987;18(1):10-12. [PMID: 3440606] DOI:10.1016/0020-1383(87)90375-5

37. Hildingsson C, Hietala SO, Toolanen G. Scintigraphic findings in acute whiplash injury of the cervical spine. Injury. 1989;20(5):265-66. [PMID: 2613307] DOI:10.1016/0020-1383(89)90164-2

38. Ronnen HR, De Korte PJ, Brink PR, Van der Bijl HJ, Tonino AJ, Franke CL. Acute whiplash injury: Is there a role for MR imaging?-A prospective study of 100 patients. Radiology. 1996;201(1):93-96. [PMID: 8816527

39. Vernon H, Mior S. The Neck Disability Index: A study of reliability and validity. J Manipulative Physiol Ther. 1991; 14(7):409-15. [PMID: 1834753]

40. Vernon H. The Neck Disability Index: State-of-the-art, 1991-2008. J Manipulative Physiol Ther. 2008;31(7): 491-502. [PMID: 18803999] DOI:10.1016/j.jmpt.2008.08.006

41. Whiteside A, Hansen S, Chaudhuri A. Exercise lowers pain threshold in chronic fatigue syndrome. Pain. 2004;109(3): 497-99. [PMID: 15157711]

42. Johnston V, Jimmieson NL, Jull G, Souvlis T. Quantitative sensory measures distinguish office workers with varying levels of neck pain and disability. Pain. 2008;137(2):257-65. [PMID: 17964075]

43. Farasyn A, Meeusen R. Pressure pain thresholds in healthy subjects: Influence of physical activity, history of lower back pain factors and the use of endermology as a placebolike treatment. J Bodywork Mov Ther. 2003;7(1):53-61. DOI:10.1016/S1360-8592(02)00050-5

44. Vanderweeën L, Oostendorp RA, Vaes P, Duquet W. Pressure algometry in manual therapy. Man Ther. 1996;1(5): 258-65. [PMID: 11440515] DOI:10.1054/math.1996.0276

45. De Kock M. [Whiplash associated disorders of “WAD”]. Tijdschrift voor Geneeskunde. 1997;53(24):1665-70. Dutch.

46. Michiels K, Beeckmans K, Kiekens C. Psychologische problemen bij patiënten met een laat whiplashsyndroom: Oorzaak of gevolg? Tijdschrift voor Geneeskunde. 2000; 56(9):647-54. Dutch. DOI:10.2143/TVG.56.9.5000732

47. Ligjaerde O, Føreland AR. Direct assessment of improvement in winter depression with a visual analogue scale: High reliability and validity. Psychiatry Res. 1998;81(3): 387-92. [PMID: 9925190] DOI:10.1016/S0165-1781(98)00119-X

48. Kori SH, Miller RP, Todd DD. Kinesiophobia: A new view of chronic pain behaviour. Pain Manag. 1990;3:35-43.

49. Silver A, Haeney M, Vijayadurai P, Wilks D, Pattrick M, Main CJ. The role of fear of physical movement and activity in chronic fatigue syndrome. J Psychosom Res. 2002;52(6): 
485-93. [PMID: 12069873]

DOI:10.1016/S0022-3999(01)00298-7

50. Vlaeyen JW, Kole-Snijders AM, Boeren RG, Van Eek H. Fear of movement/(re)injury in chronic low back pain and its relation to behavioral performance. Pain. 1995;62(3): 363-72. [PMID: 8657437]

51. Crombez G, Vlaeyen JW, Heuts PH, Lysens R. Pain-related fear is more disabling than pain itself: Evidence on the role of pain-related fear in chronic back pain disability. Pain. 1999;80(1-2):329-39. [PMID: 10204746]

52. Goubert L, Crombez G, Van Damme S, Vlaeyen JW, Bijttebier P, Roelofs J. Confirmatory factor analysis of the Tampa Scale for Kinesiophobia: Invariant two-factor model across low back pain patients and fibromyalgia patients. Clin J Pain. 2004;20(2):103-10. [PMID: 14770050] DOI:10.1097/00002508-200403000-00007

53. Sullivan MJ, Bishop SR, Pivik J. The pain catastrophizing scale: Development and validation. Psychol Assess. 1995; 7(4):524-32. DOI:10.1037/1040-3590.7.4.524

54. Van Damme S, Crombez G, Bijttebier P, Goubert L, Van Houdenhove B. A confirmatory factor analysis of the Pain Catastrophizing Scale: Invariant factor structure across clinical and non-clinical populations. Pain. 2002;96(3): 319-24. [PMID: 11973004]

55. Van Damme S, Crombez G, Vlaeyen JWS, Goubert L, Van den Broeck A, Van Houdenhove B. De Pain Catastrophizing Scale: Psychometrische karakteristieken en normering. Gedragstherapie. 2000;33:209-20. Dutch.

56. Kraaimaat FW, Bakker AH, Evers AW. Pijncoping strategieën bij chronische pijn patiënten. De ontwikkeling van de Pijn-Coping-Inventarisatielijst (PCI). Gedragstherapie. 1997; 22:267-77. Dutch.

57. Kraaimaat FW, Evers AW. Pain-coping strategies in chronic pain patients: Psychometric characteristics of the pain-coping inventory (PCI). J Behav Med. 2003;10(4): 343-63. [PMID: 14734263] DOI:10.1207/S15327558IJBM1004 5

58. Lanser K. Cervicale segmentale instabiliteit. Ned Tijdschr Man Ther. 1988;7:82-84. Dutch.

59. Verhagen AP, Lanser K, De Bie RA, De Vet HC. Whiplash: Assessing the validity of diagnostic tests in a cervical sensory disturbance. J Manip Physiol Ther. 1996;19(8):508-12. [PMID: 8902661]

60. Verhagen AP, Lanser K. Whiplash en een cervicale segmentale functiestoornis: Beschrijving van twee diagnostische tests. In: Vaes P, Kwakkel G, Smits-Engelsman, BC, Verhagen AP, editors. Jaarboek Fysiotherapie 2002. Houten (the Netherlands): Bohn Stafleu van Loghum; 2002. p. 144-53.

61. Balster SM, Jull GA. Upper trapezius activity during the brachial plexus tension test in asymptomatic subjects. Man
Ther. 1997;2(3):144-49. [PMID: 11440527]

DOI:10.1054/math.1997.0294

62. Clarkson HM, Gilewich GB. Musculoskeletal assessment: Joint range of motion and manual muscle strength. Baltimore (MD): Williams \& Wilkins; 1989.

63. Coppieters M, Stappaerts K, Janssens K, Jull G. Reliability of detecting "onset of pain” and "submaximal pain” during neural provocation testing of the upper quadrant. Physiother Res Int. 2002;7(3):146-56. [PMID: 12426912] DOI:10.1002/pri.251

64. Butler DS, Moseley GL. Explain pain. Adelaide (Australia): NOI Group Publishing; 2003.

65. Moseley GL. Unraveling the barriers to reconceptualization of the problem in chronic pain: The actual and perceived ability of patients and health professionals to understand the neurophysiology. J Pain. 2003;4(4):184-89. [PMID: 14622702] DOI:10.1016/S1526-5900(03)00488-7

66. Meeus M, Nijs J, Elsemans KS, Truijen S, De Meirleir K. Development and properties of the Dutch neurophysiology of pain test in patients with chronic fatigue syndrome. J Muscoskel Pain. 2010;18(1):58-65. DOI:10.3109/10582450903495908

67. Cohen J. Statistical power analysis for the behavioral sciences. Hillsdale (NJ): L. Erlbaum Associates; 1988.

68. Zusman M. Forebrain-mediated sensitization of central pain pathways: "Non-specific" pain and a new image for MT. Man Ther. 2002;7(2):80-88. [PMID: 12151244$]$ DOI:10.1054/math.2002.0442

69. McClune T, Burton AK, Waddel G. Whiplash associated disorders: A review of the literature to guide patient information and advice. Emerg J. 2002;19(6):499-506.

[PMID: 12421771]

DOI:10.1136/emj.19.6.499

70. McClune T, Burton AK, Waddel G. Evaluation of an evidence based patient educational booklet for management of whiplash associated disorders. Emerg Med J. 2003;20(6): 514-17. [PMID: 14623835]

DOI:10.1136/emj.20.6.514

71. Vangronsveld K, Peters M, Goossens M, Linton S, Vlaeyen J. Applying the fear-avoidance model to the chronic whiplash syndrome. Pain. 2007;130:258-61. [PMID: 17531388]

72. Houben RM, Gijsen A, Peterson J, De Jong PJ, Vlaeyen JW. Do health care providers' attitudes towards back pain predict their treatment recommendations? Differential predictive validity of implicit and explicit attitude measures. Pain. 2005;114(3):491-98. [PMID: 15777874]

Submitted for publication December 31, 2009. Accepted in revised form July 12, 2010. 
VAN OOSTERWIJCK et al. Pain neurophysiology education in chronic whiplash

This article and any supplementary material should be cited as follows:

Van Oosterwijck J, Nijs J, Meeus M, Truijen S, Craps J, Van den Keybus N, Paul L. Pain neurophysiology education improves cognitions, pain thresholds, and movement performance in people with chronic whiplash: A pilot study. J Rehabil Res Dev. 2011;48(1):43-58.

DOI:10.1682/JRRD.2009.12.0206

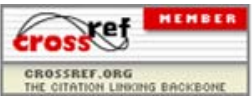





\title{
Pain neurophysiology education improves cognitions, pain thresholds, and movement performance in people with chronic whiplash: A pilot study
}

\author{
Jessica Van Oosterwijck, MS; ${ }^{1-3}$ Jo Nijs, PhD; $;^{1-3^{*}}$ Mira Meeus, PhD $;^{1-2}$ Steven Truijen, PhD, MSc; ${ }^{2}$ Julie \\ Craps, MS; ${ }^{2}$ Nick Van den Keybus, MS; ${ }^{2}$ Lorna Paul, $\mathbf{P h D}^{4}$ \\ ${ }^{1}$ Department of Human Physiology, Faculty of Physical Education \& Physiotherapy, Vrije Universiteit Brussel, Brussels, \\ Belgium; ${ }^{2}$ Division of Musculoskeletal Physiotherapy, Department of Health Care Sciences, Artesis University College \\ of Antwerp, Antwerp, Belgium; ${ }^{3}$ Department of Physical Medicine and Physiotherapy, University Hospital Brussels, \\ Brussels, Belgium; ${ }^{4}$ Nursing and Health Care, Faculty of Medicine, University of Glasgow, Glasgow, United Kingdom
}

\begin{abstract}
Chronic whiplash is a debilitating condition characterized by increased sensitivity to painful stimuli, maladaptive illness beliefs, inappropriate attitudes, and movement dysfunctions. Previous work in people with chronic low back pain and chronic fatigue syndrome indicates that pain neurophysiology education is able to improve illness beliefs and attitudes as well as movement performance. This single-case study (A-B-C design) with six patients with chronic whiplash associated disorders (WAD) was aimed at examining whether education about the neurophysiology of pain is accompanied by changes in symptoms, daily functioning, pain beliefs, and behavior. Periods $\mathrm{A}$ and $\mathrm{C}$ represented assessment periods, while period B consisted of the intervention (pain neurophysiology education). Results showed a significant decrease in kinesiophobia (Tampa Scale for Kinesiophobia), the passive coping strategy of resting (Pain Coping Inventory), self-rated disability (Neck Disability Index), and photophobia (WAD Symptom List). At the same time, significantly increased pain pressure thresholds and improved pain-free movement performance (visual analog scale on Neck Extension Test and Brachial Plexus Provocation Test) were established. Although the current results need to be verified in a randomized, controlled trial, they suggest that education about the physiology of pain is able to increase pain thresholds and improve pain behavior and pain-free movement performance in patients with chronic WAD.
\end{abstract}

Key words: chronic pain, chronic whiplash, cognitions, education, movement performance, pain behavior, pain neurophysiology, pain thresholds, rehabilitation, whiplash associated disorders.

\section{INTRODUCTION}

A whiplash trauma of the neck can result in bony or soft-tissue injuries that produce a large variety of clinical manifestations grouped under the term whiplash associated disorders (WAD) [1]. Using the Quebec Task Force on WAD (QTF-WAD) guidelines [1], WAD can be classified into five grades of severity: grade $0=$ no neck symptoms or physical sign(s); grade I = neck pain, stiffness, or tenderness but no physical sign(s); grade II = neck symptoms and musculoskeletal sign(s) such as decreased range of motion and point tenderness; grade III = neck symptoms and neurologic sign(s); and grade IV = neck symptoms

\footnotetext{
Abbreviations: $\mathrm{BPPT}=$ Brachial Plexus Provocation Test, ES = effect size, NDI = Neck Disability Index, PCI = Pain Coping Inventory, PCS = Pain Catastrophizing Scale, PCS-DV = PCSDutch version, $\mathrm{PPT}=$ pain pressure threshold, $\mathrm{QTF}-\mathrm{WAD}=$ Quebec Task Force on whiplash associated disorders, TSK = Tampa Scale for Kinesiophobia, VAS = visual analog scale, $\mathrm{WAD}=$ whiplash associated disorders .

* Address all correspondence to Jo Nijs, PhD; Vrije Universiteit Brussel, Faculty of Physical Education \& Physiotherapy, Department of Human Physiology, Building L-3rd floor, Pleinlaan 2, BE-1050 Brussels, Belgium; +32-2-629-27-53; fax: +32-2-629-28-76. Email: Jo.Nijs@vub.ac.be

DOI:10.1682/JRRD.2009.12.0206
} 
and fracture or dislocation. Between 10 and 42 percent of patients who sustain a whiplash injury develop chronic pain and approximately 10 percent of patients experience constant severe pain [1-4]. The main pain complaints that persist 6 months after the accident are neck pain (10\%-45\%), headache (8\%-30\%), and pain in the shoulder and arm (5\%-25\%) [5]. Additional complaints by patients with chronic WAD are depression, fear, difficulty concentrating, fatigue, and irritability $[1,6]$.

Little is known about the continuum of WAD from the time of injury through transition to either recovery or chronicity [7]. Several mechanisms such as altered central pain processing and central sensitization [8-11] and the role of cognitions and behaviors [12-15] have been suggested, and evidence that supports these theories is rising. The dearth of trials evaluating conservative treatments for patients with chronic WAD is striking. Stewart stated that very few trials have evaluated interventions for patients with chronic whiplash [16], while Verhagen et al. performed a systematic review concluding that none of the investigated conservative treatments were effective for the treatment of acute, subacute, or chronic symptoms of WAD [17]. The cases that do not recover by 3 months are responsible for the majority of whiplash costs [1]; therefore, treatments that prevent transition to chronicity or that are effective for chronic whiplash have the potential to significantly reduce social and economic costs [15]. Holm et al. suggested that education about the physiology of chronic whiplash pain can improve expectations for recovery, especially in the (sub)acute stages of WAD [18]. This is supported by Oliveira et al., who evaluated the effects of a psychoeducational film shown to patients with acute whiplash who consulted an emergency unit after injury [19]. The film consisted of information about symptomatology, physiology of a cervical strain, physiology and physical/emotional triggers of muscle tension, medical treatment, expectations of recovery, and examples of exercises. This psychoeducational intervention resulted in improved recovery in the patients with subacute whiplash. In patients with chronic WAD, programs including exercise and extensive education to change pain cognitions and pain coping strategies resulted in a positive outcome $[15,20]$.

Catastrophic beliefs about pain are associated with heightened pain and disability in people with chronic WAD and play an important role in the transition from (sub)acute to chronic WAD [12,21-22]. In addition, psychological factors such as depression, anxiety, expecta- tions concerning recovery, and high psychological distress have been identified as important prognostic factors for patients with WAD [7,18,23-24]. Söderlund and Lindberg described the importance of using positive coping strategies in dealing with whiplash-related complaints [22,25]. Patients who are misinformed about pain consider pain to be more threatening and present lower pain tolerance, more catastrophic thoughts, and less adaptive coping strategies [26]. Therefore, the education of pain neurophysiology is aimed at both altering patients' knowledge about their pain states and reconceptualizing pain [27]. Psychoeducational interventions that have been studied in WAD often include informing the patient about symptomatology, recovery, activity, and treatment and/or addressing pain behavior and beliefs. When only cognitive and behavioral responses are encouraged, without reconceptualizing pain, these responses may be counterintuitive for patients with chronic pain because pain is still a sign of harm to them [28]. Therefore, Moseley relies on “deep learning” education on pain neurophysiology that is aimed at reconceptualizing pain, on the assumption that appropriate cognitive and behavioral responses will follow when pain is appraised as less dangerous [29]. Even when education about physiology is included in psychoeducational programs, it is often limited to the physiology of a cervical strain. Except for the changes that occur in the local tissues because of a whiplash injury, changes in local and central pain mechanisms play an important role and should be addressed, especially for patients with chronic pain. Pain neurophysiology education targets this by reconceptualizing the underlying physiological problem of a patient's pain on the assumption that an appropriate cognitive and behavioral/ motor response will follow [28].

Education about the neurophysiology of pain has been studied in chronic pain populations, such as chronic low back pain [27,29-32] and chronic fatigue syndrome [33]. In patients with chronic fatigue syndrome, a single educational session was able to alter cognitions, such as catastrophizing, and pain behavior, such as coping [33]. In patients with chronic low back pain, pain physiology education alters pain beliefs and attitudes and, in conjunction with physiotherapy, improves functional and symptomatic outcomes [27,29-32]. Moseley has also shown that altered pain beliefs are directly associated with altered movement performance, even if no opportunity to be physically active is available [27,32]. This implies that motor performance may be directly limited by pain beliefs. Education about the neurophysiology of 
pain fits within our current understanding of chronic WAD and it might be able to address cognitive emotional sensitization (central hypersensitivity influenced and modulated by cognitions and emotions) in these patients [34]. Taking this into consideration, patient education seems an economical, time-saving method to use in the treatment of WAD. By using education to improve incorrect pain cognitions and attitudes, we might prevent chronicity or improve treatment success.

The single-case study design is often used to systematically evaluate new treatments for specific (usually chronic) patient populations. Hence, it can be used in preparation of a large randomized, controlled clinical trial. One of the crucial features of the single-case design is continuous measurement throughout different conditions, which makes it possible to use individuals as their own controls. The function of the baseline is to describe the present state and predict future projection if no intervention were to take place. By this function, it is possible to judge whether change has occurred from the baseline period to the intervention period. The baseline period of a single-case study typically consists of several baseline assessments that account for the natural variability of the patients' health status. If this (often minimal) variability is suddenly "disturbed" when the intervention is conducted, it is accepted that this is a consequence of the intervention.

Although the use of psychoeducational interventions has been studied in patients with acute WAD, the use of pain neurophysiology education in patients with chronic WAD has not been examined previously. Therefore, the present study is aimed at examining whether two one-onone education sessions about the neurophysiology of pain may lead to a change in pain beliefs and behavior, symptom severity, daily functioning, pain threshold, and movement performance in patients with chronic WAD. The treatment is evaluated using a single-case study design.

\section{METHODS}

\section{Subjects}

We selected patients with WAD grades I to II according to the QTF-WAD [1], who were experiencing chronic pain as result of a whiplash injury, from the medical files available at a university-based department of physical medicine. In WAD grades III to IV, neurological damage, fractures, and dislocations might explain the symptoms experienced by patients, whereas in WAD grades I to II, no physical signs can be identified even when sophisticated imaging techniques are used [35-38]. Given the focus of the education on central sensitization as an explanatory model for WAD symptoms, we deemed it appropriate to limit the study to patients with WAD grades I to II. In addition, when anatomical abnormalities are established, patients are treated by (specialized) physicians, whereas patients without objective signs of tissue damage are referred to a physical therapist for conservative treatment. For these reasons, the study focused on patients with WAD grades I to II. In total, we selected 23 patients experiencing chronic complaints due to a whiplash injury who sought care at a local universitybased clinic. We screened the medical files of these 23 patients according to the inclusion and exclusion criteria of the study. We qualified patients with chronic WAD grades I to II having Dutch as their native language and 18 to 65 years old to participate in the present study. Out of the 23 patients, 11 fulfilled the inclusion criteria. We contacted these patients by telephone and informed them about the study. Six patients agreed to participate in the study, while five patients declined because they were not interested or they had no time to attend the seven study visits.

\section{Procedure}

We invited patients to participate in the study and gave them a detailed information leaflet. The information leaflet stated that the patients were allowed to continue any ongoing treatments but asked them not to initiate any new treatments (medication, rehabilitation, alternative medicine). We then collected patient demographic data (age, time since onset of complaints, medication usage, etc.) using a questionnaire.

This single-case study consisted of an A-B-C design in which periods $A$ and $C$ represent the assessment periods and period B represents the intervention (Figure 1). Period A represents the baseline period, while period C represents the treatment-free follow-up. During the assessment (period A), we asked patients to fill out a battery of questionnaires, i.e., the Neck Disability Index (NDI), the WAD Symptom List, the Pain Catastrophizing Scale (PCS), the Pain Coping Inventory (PCI), and the Tampa Scale for Kinesiophobia (TSK). We also subjected patients to a set of clinical assessments, i.e., the Neck Extension Test, the Brachial Plexus Provocation Test (BPPT), and algometry. We randomized the test order to preclude test-order bias. We randomly allocated patients 


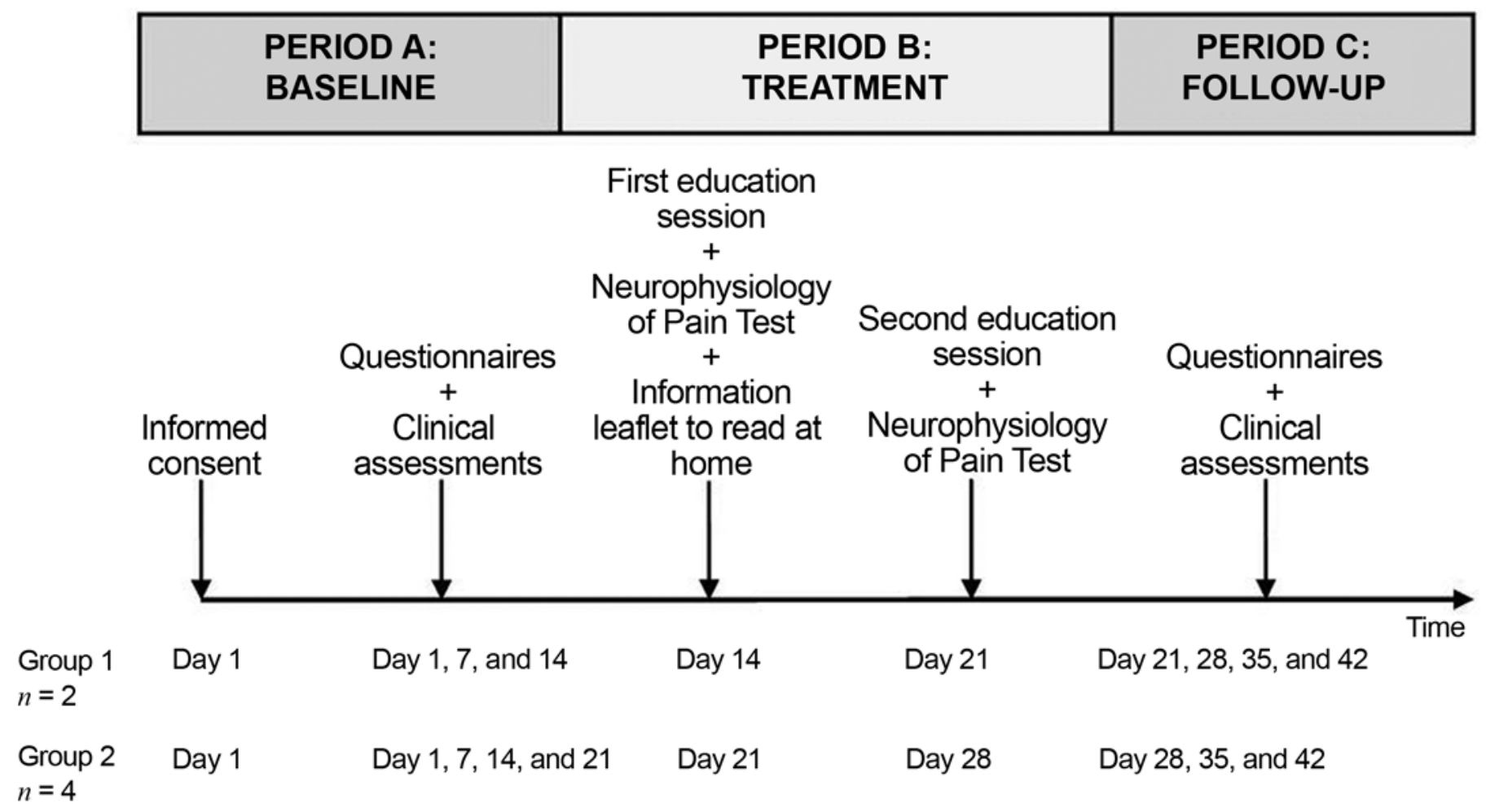

Figure 1.

Study protocol. Questionnaires: Neck Disability Index, Whiplash Associated Disorders Symptom List, Pain Catastrophizing Scale, Pain Coping Inventory, and Tampa Scale for Kinesiophobia. Clinical assessments: Neck Extension Test, Brachial Plexus Provocation Test, and pain pressure thresholds.

into two groups and blinded the assessor to the group allocation. Both groups received the same treatment and underwent the same measurements but differed in the sequence of events that took place during the study period. Hence, we blinded the assessor to the exact moment at which the intervention took place. The first group consisted of two patients who received their baseline measurements (period A) on days 1, 7, and 14. On day 14, they received the first treatment session (period B). The second session was given on day 21 followed by the first posttreatment measurements. The follow-up measurements (period C) were given on days 28, 35, and 42. The second group consisted of four patients who received the baseline measurements (period A) on days $1,7,14$, and 21, followed by the treatment on days 21 and 28, and finally the follow-up (period C) on days 28, 35, and 42. We subjected the first group to three preassessments and four postassessments, while the second group underwent four preassessments and three postassessments as presented in Figure 1.

\section{Measurements and Questionnaires}

We chose the NDI and the pain pressure thresholds (PPTs) as the primary outcome measures. The NDI was developed in 1991 as a modification of the Oswestry Back Pain Index and was the first instrument designed to assess self-rated disability in patients with neck pain [3940]. The NDI is scored from 0 (good function) to 50 (poor function), and the percentage of disability can be obtained when the score is multiplied by two. The NDI is a valid and reliable instrument sensitive to measure changes within a population of patients with neck pain [39-40].

We measured PPTs bilaterally with an analog Fisher algometer (Force Dial model FDK 40 Push Pull Force Gage, Wagner Instruments; Greenwich, Connecticut) in the skin web between thumb and index finger [41], at the proximal third of the calf, and at the upper trapezius muscle (pars descendens) midway between cervical 7 and the tip of the acromion [42]. We assessed these sites in random order. We gradually increased the force at a rate of 
$1 \mathrm{~kg} / \mathrm{m}^{2} / \mathrm{s}$ [43]. We defined PPT as the point at which the pressure sensation turned to pain [8]. We determined the PPT as the mean of the two last values out of three consecutive measurements (10 $\mathrm{s}$ in between), since this procedure has found to be reliable in nondisabled controls [43]. Algometry provides a reliable and valid measure of PPTs [44].

The WAD Symptom List is a self-reported measure for assessing symptom severity in patients with WAD. The questionnaire is composed of the most reported WAD symptoms in the literature and some autonomic symptoms [25,45-46]. Every symptom is presented by a visual analog scale (VAS) $(100 \mathrm{~mm})$, a method that is known for its validity and reliability [47]. Previously, our research group found a good internal consistency (Cronbach $\alpha=0.92$ ) for the WAD symptom list (unpublished data).

The TSK is a 17-item questionnaire that measures the fear of (re)injury due to movement [48]. Items are scored on a 4-point Likert scale, and a total score is calculated (1-4 for each item) after inversion of the individual scores of items $4,8,12$, and 16 . The total scores for the TSK range from 17 to 68 , with scores of $\leq 37$ suggesting low fear of movement and scores $>37$ indicating high fear of movement [49-50]. The TSK-Dutch version used in this study is a reliable and valid measure [12,50-52].

We used the PCS-Dutch version (PCS-DV) to measure catastrophic thinking about pain [51,53]. This selfreported questionnaire consists of 13 items describing different thoughts and feelings that individuals may experience when experiencing pain. Items are scored on a 5-point scale, and one general score can be obtained for the degree of catastrophic thoughts about pain by adding up all individual item scores. This general score can be subdivided into three subscales: Helplessness, Magnification, and Rumination. Higher scores correspond to more severe catastrophic thoughts about pain. The psychometric properties of the PCS-DV are well established [51,54-55].

The PCI consists of six scales (33 items) measuring cognitive and behavioral pain-coping strategies that represent two higher order pain coping dimensions: active (distraction, transformation, and reducing demands) and passive (resting, retreating, and worrying) [56]. Patients are asked to indicate how often they apply a certain strategy when dealing with pain on 4-point Likert scale ranging from 1 (hardly ever) to 4 (very often). Internal consistency, test-retest reliability, validity, and sensitivity are reported as good in different patient populations [56-57].
The Neck Extension Test is used to diagnose sensory disturbances in patients with whiplash and is able to discriminate between subjects with symptoms after a whiplash injury and subjects without head or neck complaints [58-59]. During the test, patients sit looking straight forward and are asked to move their head backward as far as possible resulting in cervical extension. The patient's willingness to perform the movement is registered and the degree of pain experienced during the test performance is measured using a VAS. When there is a problem with the motor control of the movement, patients are frequently anxious about moving their head toward extension [60]. Then, the patient is asked to make the same movement, placing their index finger on a selfchosen cervical segment. When the involved segment has impaired motor control, then the cervical spine will extend better and the movement will be less or not at all painful during this test situation [60]. Therefore, patients are asked which movement felt better and pain is measured using a VAS.

The BPPT is performed with the patient lying faceup. First, a gentle shoulder depression is carried out, followed by a glenohumeral abduction and external rotation, wrist and finger extension, and elbow extension [11]. The elbow extension is stopped when the patient reports that the test is unpleasant or painful. The obtained range of elbow extension during the BPPT is measured using a standard goniometer aligned along the midhumeral shaft, medial epicondyle, and ulnar styloid [61-62]. If no pain is experienced, elbow extension is continued to the normal end of range. At the completion of the test, the subjects are asked to rate pain on a VAS [11]. According to Coppieters et al., pain provocation during neurodynamic testing is a stable phenomenon and the range of elbow extension corresponding with the moment of "pain onset" and "submaximal pain" may be measured reliably, both in laboratory and clinical conditions [63]. We performed the test three times on each arm and calculated an average for each side.

\section{Intervention}

The intervention consisted of two educational sessions and an information leaflet about the neurophysiology of pain. We used the Neurophysiology of Pain Test (patient version) to tailor the second educational secession. All subjects participated in two one-on-one educational sessions about the neurophysiology of pain. Each session lasted about 30 minutes. The intervention was delivered 
by a therapist with a bachelor's degree in physiotherapy, who received training from two therapists with master's degrees in physiotherapy and experience in providing pain physiology education. The therapist who conducted the educational sessions was blinded to the results of the measurements and questionnaires. The content and pictures of the educational sessions were based on the book Explain Pain [64-66]. The education covered the physiology of the nervous system in general and of the pain system in particular. The information was presented in detail using pictures, examples, and metaphors. We started the sessions by questioning the patient on their illness perceptions and pain cognitions. The therapist used this information to individually tailor the educational session. Topics addressed during the educational sessions included the characteristics of acute versus chronic pain; the purpose of acute pain; how acute pain originates in the nervous system (nociceptors, ion gates, neurons, action potential, nociception, peripheral sensitization, synapses, synaptic gap, inhibitory/excitatory chemicals, spinal cord, descending/ascending pain pathways, brain role, pain memory, and pain perception); how pain becomes chronic (plasticity of the nervous system, modulation, modification, central sensitization, pain neuromatrix theory); and potential sustaining factors of central sensitization like emotions, stress, pain cognitions, and pain behavior. We developed the educational session in line with the content of the Neurophysiology of Pain Test in such a way that after having received the education, patients should be able to answer all questions of the test correctly. We presented the educational information verbally (explanation by the therapist) and visually (summaries, pictures, and diagrams on computer and paper). Patients could ask questions during the sessions, and we used their input to individualize the information. After the first session, we asked patients to fill out the Neurophysiology of Pain Test, a questionnaire to assess their knowledge on pain neurophysiology [65]. This is a valid and reliable questionnaire with 19 posings concerning nociception and the modulation of nociception that need to be answered with "true," "false," or "undecided" [66]. A score can be calculated by adding the correct answers, for a total possible maximum score of 19 . We used the Neurophysiology of Pain Test as a part of the intervention to control which topics needed additional explanation during the second session. Patients also received an information leaflet about the neurophysiology of pain and were asked to read it carefully at home. Patients with chronic
WAD often report impairments in attention and concentration and could be less focused on some aspects of the verbal education. Therefore, additional written information that can be read afterwards is a valuable and essential part of the intervention. During the second session, the therapist answered and explained additional questions that arose after reading the information leaflet. Based on incorrect answers scored on the Neurophysiology of Pain Test, the therapist selected those items and explained them once again and, if necessary, in more detail. Afterwards, we asked patients to fill out the Neurophysiology of Pain Test once again, to examine whether they understood all the information provided.

\section{Statistical Analysis}

We analyzed all data using SPSS version 16.0 for Windows (SPSS Inc; Chicago, Illinois). We calculated appropriate descriptive statistics and, to account for missing data (see the "Results" section), used the "last observation carried forward" method for the intention-to-treat analysis. We compared baseline scores between the seven different assessment points using the Wilcoxon signed ranks test to assess the natural variability of the symptoms. For every variable, we calculated an average score from the baseline measurements and another from the follow-up measurements. We examined the treatment effect by comparing the average baseline score with the average follow-up scores. Although we calculated one average baseline score and one average follow-up score for statistical comparison, Figures 2 through 8 show the evolution of the scores over time.

Using a Wilcoxon signed ranks test, we compared average test scores on baseline variables with average test scores on posttreatment variables to establish the therapy effect. We set the significance level at 0.05 . We calculated effect sizes (ESs) as Cohen's $d$, with $d$ defined as the difference between the two means divided by the pooled standard deviation for those means. A $d$-value of 0.20 is described as small, 0.50 as medium (moderate), and 0.80 as large [67]. Table 1 presents $d$-values translated into percentiles. For example, for an ES of 0.6, the value of 73 percent indicates that the average person in the experimental group would score higher than 73 percent of the control group, assuming that the two were initially equivalent. 


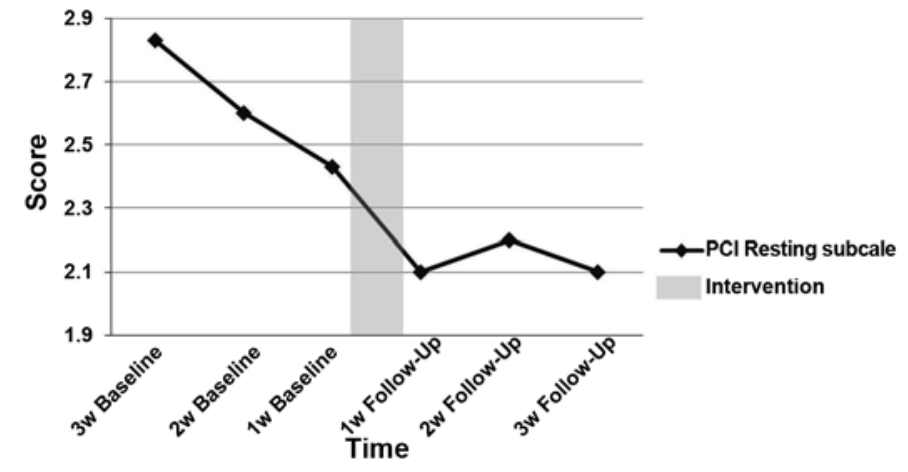

Figure 2.

Evolution of mean Pain Coping Inventory (PCI) Resting subscale scores over time in six patients with chronic whiplash associated disorders. Baseline assessments at 3, 2, and 1 week before intervention; follow-up assessments 1, 2, and 3 weeks after intervention.

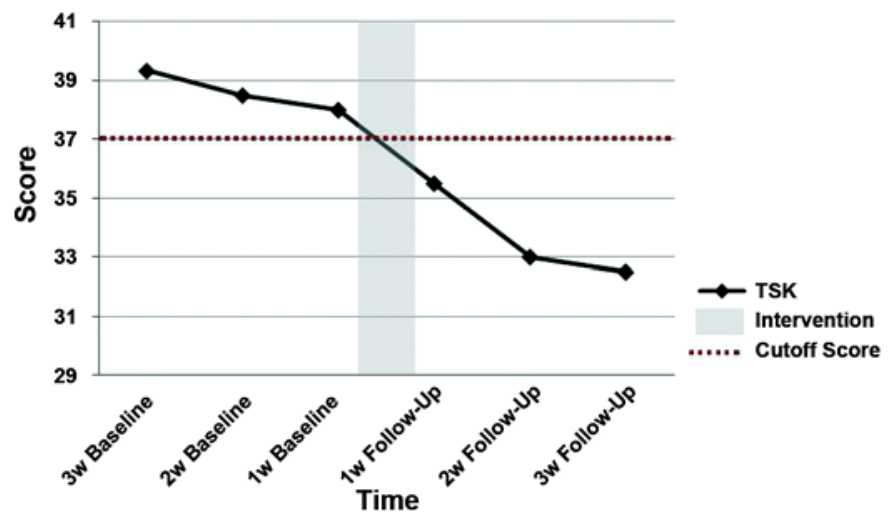

Figure 3.

Evolution of mean Tampa Scale for Kinesiophobia (TSK) scores over time in six patients with chronic whiplash associated disorders. Baseline assessments at 3, 2, and 1 week before intervention; follow-up assessments 1, 2, and 3 weeks after intervention.

\section{RESULTS}

Six patients with WAD grades I to II according to QTF-WAD guidelines participated in the study. The mean time since onset of pain was $50.3 \pm 28.2$ months. The group consisted of 5 females and 1 male, and the mean age was $35.7 \pm 7.3$ years. All patients were Caucasian. One patient reported the use of lidocaine patches (analgesic) and one patient occasionally used tetrazepam (anxiolytic and muscle relaxant). Table 2 presents detailed information about each patient.

We found no significant differences between the different baseline measurements that we collected weekly;

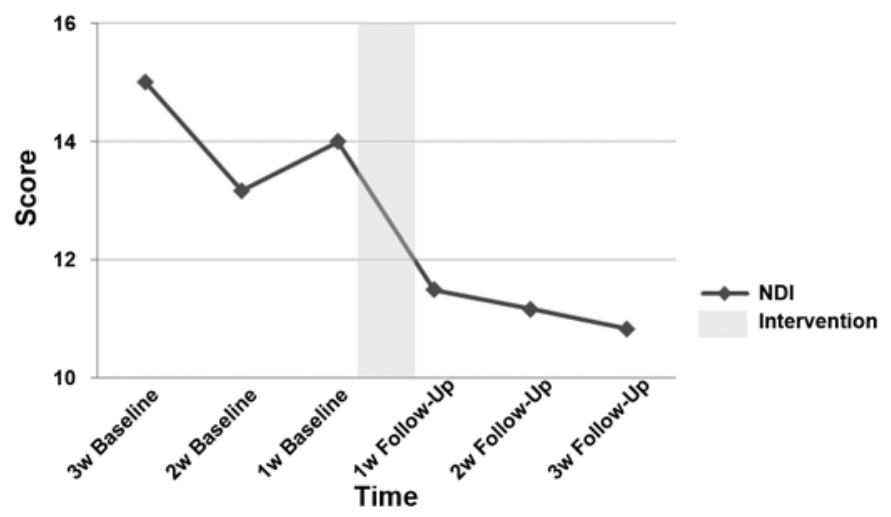

Figure 4.

Evolution of mean Neck Disability Index (NDI) scores over time in six patients with chronic whiplash associated disorders. Baseline assessments at 3, 2, and 1 week before intervention; follow-up assessments 1,2 , and 3 weeks after intervention.

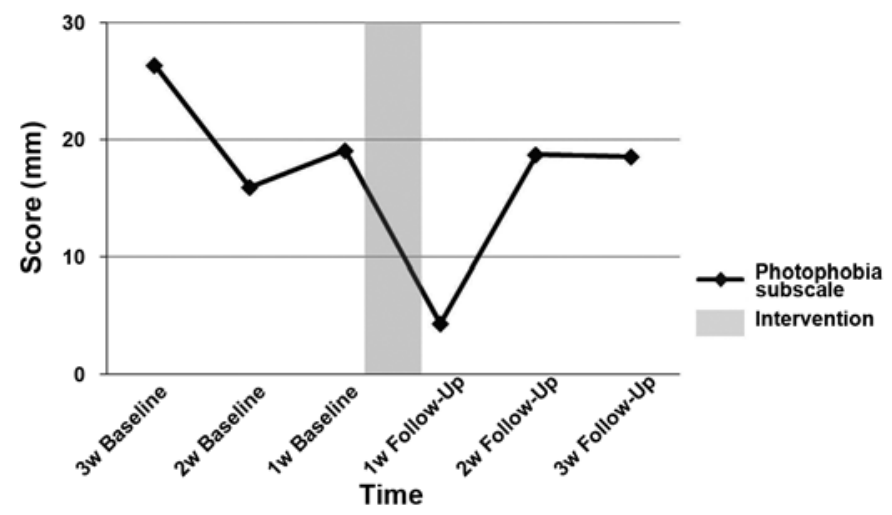

Figure 5.

Evolution of mean Whiplash Associated Disorders (WAD) Symptom List Photophobia subscale scores by visual analog scale over time in six patients with chronic WAD. Baseline assessments at 3, 2, and 1 week before intervention; follow-up assessments 1,2 , and 3 weeks after intervention.

thus, we calculated an average score for every variable. We also calculated an average score for every variable for the follow-up measurements. The Wilcoxon signed ranks test showed some significant changes between the average test scores before and after the intervention (Table 1).

After patients received education about the neurophysiology of pain, we found some significant changes in the primary outcome measures. A significant decrease in average NDI scores was established $(p=0.046)$, and five out of six patients showed an average improvement of 17.7 percent on the NDI. After the education session, the percentage of neck disability (NDI) reduced from 28.3 to 


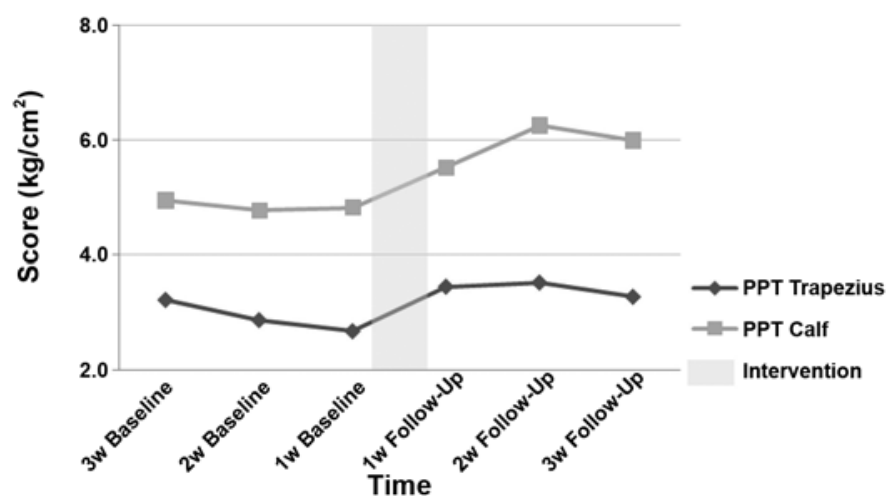

Figure 6.

Evolution of mean pain pressure threshold (PPT) scores over time in six patients with chronic whiplash associated disorders. Baseline assessments at 3, 2, and 1 week before intervention; follow-up assessments 1,2 , and 3 weeks after intervention.

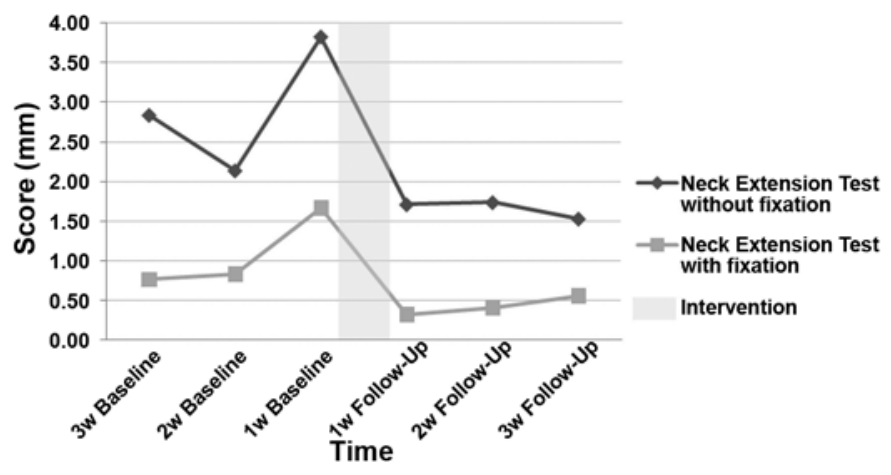

Figure 7.

Evolution of mean Neck Extension Test scores by visual analog scale over time in five patients with chronic whiplash associated disorders. Baseline assessments at 3, 2, and 1 week before intervention; followup assessments 1, 2, and 3 weeks after intervention.

22.7 percent. PPTs measured at the trapezius muscle $(p=$ $0.03)$ and the calf $(p=0.04)$ improved significantly after the intervention. While all patients showed improved PPTs measured near the neck (33.3\% improvement), five out of six patients showed improved PPTs measured at the calf (25.5\% improvement).

After the intervention, we found a decrease in every PCI subscale score regarding passive coping. The Resting subscale significantly decreased ( $p=0.03, d=1.29$ ) in all patients with WAD, with a change in scores of 18.3 percent. While in five out of six subjects, the mean scores on the Retreating and Worrying subscales decreased by 8.1 and 8.7 percent, respectively, the changes were not

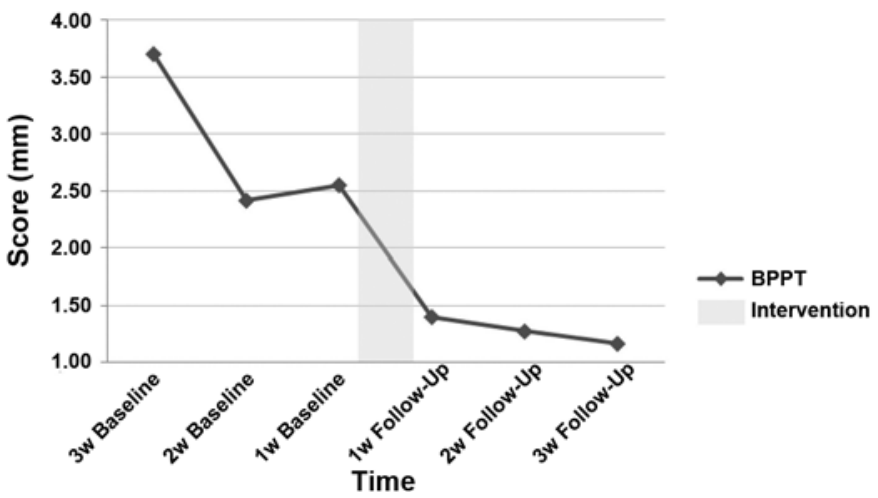

Figure 8.

Evolution of mean Brachial Plexus Provocation Test (BPPT) scores by visual analog scale over time in six patients with chronic whiplash associated disorders. Baseline assessments at 3, 2, and 1 week before intervention; follow-up assessments 1,2 , and 3 weeks after intervention.

significant (Retreating subscale: $p=0.08, d=0.25$; Worrying subscale: $p=0.09, d=0.31$ ). We found no significant changes for the PCI subscales regarding active coping and for the PCS. We did, however, find a significant decrease in the score on the TSK ( $p=0.03, d=0.82$ ); all patients with WAD showed an average improvement on the TSK of 13.8 percent. Using the WAD Symptom List, we observed a significant reduction in photophobia $(p=$ $0.04, d=0.34$ ).

One patient from group 1 did not attend the physical examinations performed on day 35 . We replaced the missing values using the last observation carried forward method. After patients received the education intervention, pain scores during the BPPT reduced significantly ( $p=0.04, d=1.45$ ) from $31.15 \mathrm{~mm}$ to $12.47 \mathrm{~mm}$. During the Neck Extension Test, patients' willingness to perform the movement was registered to indicate whether there was a problem with their motor control, which often translated to anxiousness to perform the movement. This was the case for one patient who refused to perform the Neck Extension Test during the examinations in fear of pain provocation. At baseline, patients scored significantly lower $(p=0.04)$ on the VAS during performance of the Neck Extension Test when they were able to fixate a selfchosen cervical segment. At the follow-up measurements, the difference was no longer found to be significant ( $p=$ 0.07). On the question "Could you perform the movement better during the test with or without fixation?" all patients replied that the test with fixation helped them to perform the cervical extension movement better. This was 
Table 1.

Results of questionnaires and clinical assessments analyzed with Wilcoxon signed ranks test in six patients with chronic whiplash associated disorders (WAD).

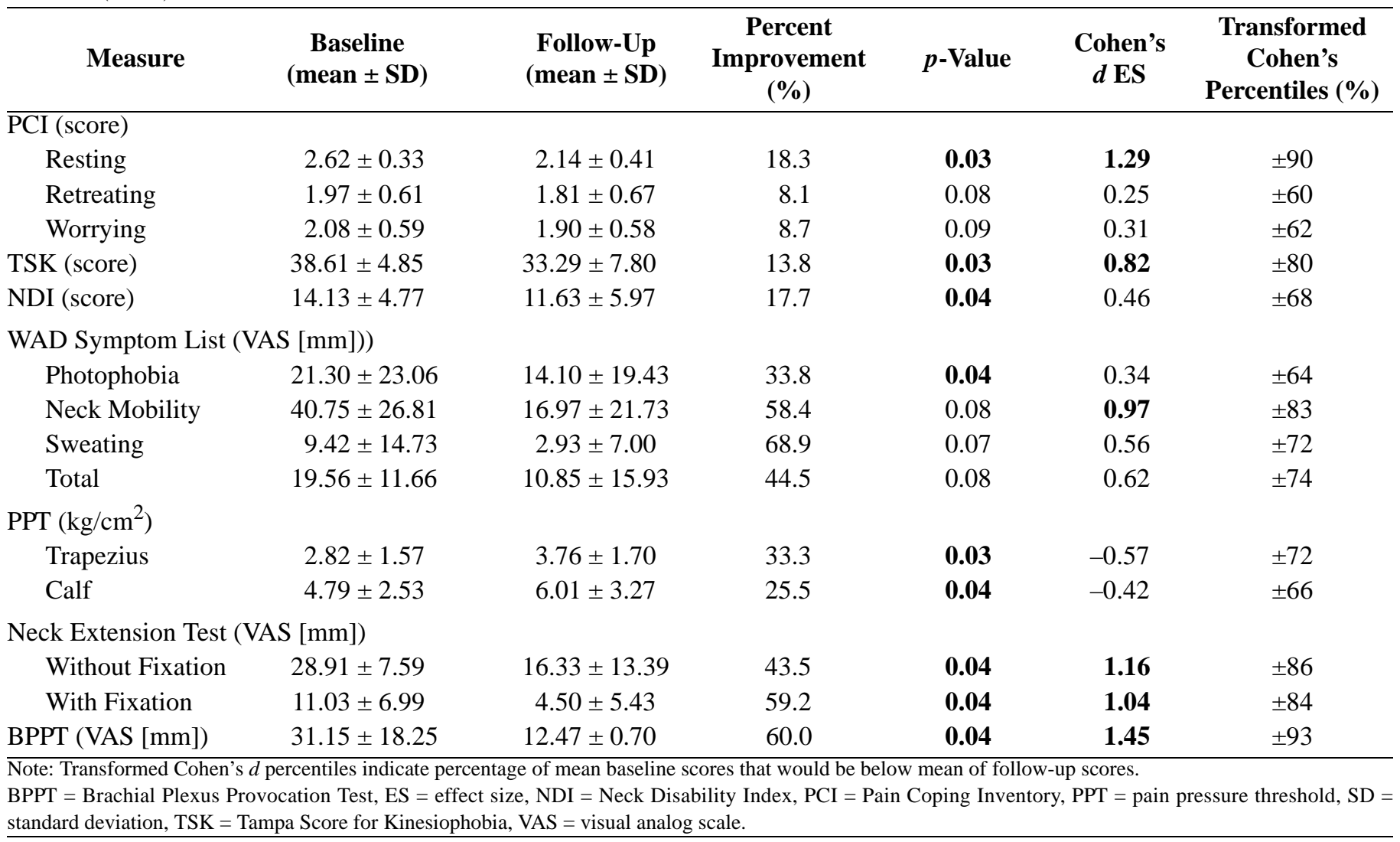

Table 2.

Demographic characteristics of patients with whiplash associated disorders.

\begin{tabular}{|c|c|c|c|c|c|c|c|}
\hline Patient & Sex & Age (yr) & $\begin{array}{c}\text { Time Since } \\
\text { Onset of } \\
\text { Complaints } \\
\text { (mo) }\end{array}$ & $\begin{array}{l}\text { Marital } \\
\text { Status }\end{array}$ & $\begin{array}{c}\text { Parental } \\
\text { Status (No. } \\
\text { of children) }\end{array}$ & $\begin{array}{l}\text { Analgesic } \\
\text { Use }\end{array}$ & $\begin{array}{c}\text { Antidepressant } \\
\text { Use }\end{array}$ \\
\hline 1 & $\mathrm{M}$ & 49 & 12 & Married & 4 & No & No \\
\hline 2 & $\mathrm{~F}$ & 29 & 46 & Not married & 0 & No & Yes \\
\hline 3 & $\mathrm{~F}$ & 35 & 72 & Not married & 0 & No & No \\
\hline 5 & $\mathrm{~F}$ & 31 & 64 & Not married & 0 & No & No \\
\hline 6 & $\mathrm{~F}$ & 32 & 84 & Not married & 0 & Yes & No \\
\hline
\end{tabular}

the case for both the baseline and follow-up measurements. Comparing the Neck Extension Test before and after the intervention, we recorded a significant reduction of 43.5 percent on the VAS for the test without fixation ( $p=$ $0.04, d=1.16$ ) and 59.2 percent for the test with fixation $(p=0.04, d=1.04)$.

\section{DISCUSSION}

These data from a single-case study on six patients with chronic WAD suggest that pain physiology education is accompanied by improvements in pain cognitions, pain thresholds, and pain-free movement performance. 
Because there were no significant changes between the different assessment scores that were repeated weekly during the baseline period, we can accept that these improvements were due to the intervention.

During the baseline period, the average score on the TSK indicated high fear of movement in all patients with WAD. Throughout the education, we explained the positive effect of movement on the healing process of damaged tissues and informed patients that movement would not per se cause (re)injury (even if they are in pain). During the follow-up period, we observed a significant decrease in kinesiophobia and, using the cutoff score of 37, identified low fear of movement in all participants. In addition, resting was significantly less used in response to pain, and while it was not found significant, patients reported using fewer passive coping strategies such as worrying and retreating.

Hypervigilance, catastrophizing, and avoidance behavior are important psychosocial factors of cognitive emotional sensitization. Descending facilitatory pathways have been identified connecting the brain stem with the spinal cord. Behavioral evidence shows that forebrain centers, responsible for emotional and cognitive control, are capable of exerting powerful clinically significant influences on various nuclei of the brain stem [68]. In addition, the limbic system - a group of structures in the brain involved in emotions, moods, and regulation of emotional reactions-is neurophysiologically connected to nuclei in the brain stem from which the pain facilitatory pathways depart [68]. Consequently, negative emotions, thoughts, attention, stress, etc., can modulate the activity in the descending pathways, facilitating pain and resulting in cognitive emotional sensitization [68]. In cases of hypervigilance, catastrophizing, or avoidance behavior, intensive education about the exact nature of chronic whiplash pain is likely to facilitate effective rehabilitation. McClune et al. developed an evidence-based educational booklet, The Whiplash Book [69-70]. The content emphasizes the positive prognosis of whiplash injuries and promotes activity [69]. Patients with acute WAD showed a substantial improvement in beliefs after reading the book. In contrast, patients with WAD attending a private practice for manipulation showed only a small change in beliefs, and the authors argued that this may have been due to the chronicity of their symptoms [70]. Changing inappropriate pain beliefs should be the initial phase of rehabilitation in those with chronic WAD. If not, poor understanding of pain may lead to the acqui- sition of maladaptive attitudes, cognitions, and behavior in relation to pain and consequently poor compliance to any active treatment.

After reconceptualizing pain during the educational sessions, patients' improvements in pain behavior during the follow-up period were accompanied by a decrease in symptoms. We established a trend for a decrease in overall symptom severity (the total score on the WAD Symptom List) with a Cohen's $d$ ES of 0.62 (transformed Cohen's $d=74 \%$ ). Patients reported less sweating (transformed Cohen's $d=72 \%$ ) and photophobia (transformed Cohen's $d=64 \%$ ). Sweating and photophobia are symptoms that indicate the presence of central sensitization. It seems plausible that improving pain beliefs and behavior is important, not only for enabling proper functioning of the central pain-inhibitory pathways, but also for improving movement performance. Inappropriate cognitions appear closely related to movement performance [27,32]. Patients reported a trend toward improvement in neck mobility on the WAD Symptom List and a significant decrease on self-rated disability (NDI). Neck disability experienced by patients decreased from 28.26 to 22.72 percent. These results are comparable to the findings of Moseley [30], although that study used four educational sessions of 1 hour each in combination with physiotherapy to reduce disability in patients with chronic low back pain. The present study achieved similar responses in patients with chronic WAD using only two educational sessions of 30 minutes each. An educational session of 30 minutes would be more suitable for application to clinical practice. Not only are treatment sessions with a physical therapist restricted in time, patients with chronic WAD additionally often experience attention and concentration difficulties.

Using the Neck Extension Test, we established impairment in cervical motor control at baseline. After the intervention, we could detect no significant impairment and moreover, patients experienced significantly less pain during cervical movement performance. We observed the same during the BPPT, where we established an improvement in pain-free movement of 60 percent. We found a large ES ranking in the ninety-third Cohen's percentile. PPTs measured near the neck and the calf increased significantly by 33.2 and 25.5 percent, respectively. By altering pain cognitions, such as pain coping and avoidance behavior, it could be possible that patients are more exposed to activity that in turn leads to increased or altered performance [13,71]. In the longer 
term, this could result in increased PPTs and pain tolerance. The combination of self-reported measures and clinical assessments is a strength of this study. For future research it would be useful to examine whether pain education improves cervical mobility during performance of the Neck Extension Test as well.

Education about pain neurophysiology is one aspect of chronic pain rehabilitation, and it would be useful to further examine its effect in combination with other therapies. Although it seems interesting to examine the effect of combined treatment, we first wished to examine whether education on pain neurophysiology has any potential for patients with chronic WAD. Although the present pilot study was small, it is remarkable that we observed some important significant changes and ESs. Besides, the single-case study design is a research design that has proven its usefulness in the behavioral sciences. In medical science it is often used to systematically evaluate new treatments for specific (usually chronic) patient populations. The baseline period typically consists of several baseline assessments that account for the natural variability of the patients' health status. If this natural variability of the chronic patient is suddenly "disturbed" during the intervention period, the change might be attributed to the intervention. Hence, the single-case study design can be used to examine the feasibility of a new treatment for a particular population in preparation of a large randomized, controlled clinical trial. Caution should be taken with generalizing the study findings. The study findings are solely applicable to people with WAD grades I to II. Currently, data addressing the applicability of pain physiology education in patients with chronic WAD grades III to IV are currently unavailable. In addition, we used a small sample size and the effects of education are dependent on not only the format, the content, and the patient, but also the practitioner providing the education. The attitude of the healthcare provider is crucial in educating patients [72]. Although the current results need to be verified in a randomized clinical trial, the present study suggests that education about the neurophysiology of pain is able to increase PPTs and improve pain behavior and pain-free movement performance.

\section{CONCLUSIONS}

Chronic WAD is a debilitating and costly condition, and treatment remains challenging for clinicians, including rehabilitation specialists and physiotherapists. Because very few trials have evaluated conservative interventions for patients with chronic WAD, clinical studies examining the effectiveness of conservative treatment strategies are required. Changing inappropriate pain beliefs should be the initial phase of rehabilitation in those with chronic WAD. If not, poor understanding of pain may lead to the acquisition of maladaptive attitudes, cognitions, and behavior in relation to pain and subsequent poor compliance to any active treatment. The results of this pilot study suggest that rehabilitation specialists and physical therapists are able to influence negative thoughts and pain behavior by educating patients with chronic WAD about the neurophysiology of pain. The improvement in pain behavior resulted in improved neck disability and increased pain-free movement performance and pain thresholds.

\section{ACKNOWLEDGMENTS}

\section{Author Contributions:}

Study concept and design: J. Nijs.

Acquisition of data: N. Van den Keybus, J. Craps.

Analysis and interpretation of data: J. Van Oosterwijck.

Drafting of manuscript: J. Van Oosterwijck.

Critical revision of manuscript for important intellectual content:

M. Meeus, J. Nijs, L. Paul.

Statistical analysis: S. Truijen, J. Van Oosterwijck.

Study supervision: J. Nijs, J. Van Oosterwijck.

Financial Disclosures: The authors have declared that no competing interests exist.

Funding/Support: This material was based on work supported by the Faculty of Physical Education \& Physiotherapy, Vrije Universiteit Brussel (PhD grant to Ms. Van Oosterwijck, Onderzoeksraad project 1596). Dr. Meeus is a postdoctoral research fellow of the Fund for Scientific Research Flanders.

Additional Contributions: The authors are grateful to the Department of Physical Medicine, University Hospital Antwerp, for providing study facilities and study subjects.

Institutional Review: The Ethics Committee of the University Hospital of Antwerp approved this study. Subjects signed an informed consent form.

Participant Follow-Up: The authors plan to inform participants of the publication of this study.

\section{REFERENCES}

1. Spitzer WO, Skovron ML, Salmi LR, Cassidy JD, Duranceau J, Suissa S, Zeiss E. Scientific monograph of the Quebec Task Force on whiplash-associated disorders: Redefining 
“whiplash” and its management. Spine. 1995;20(8 Suppl): 1S-73S. [PMID: 7604354]

2. Barnsley L, Lord S, Bogduk N. Whiplash injury. Pain. 1994;58(3):283-307. [PMID: 7838578]

3. Lovell ME, Galasko CS. Whiplash disorders-A review. Injury. 2002;33(2):97-101. [PMID: 11890909] DOI:10.1016/S0020-1383(01)00111-5

4. Rodriquez AA, Barr KP, Burns SP. Whiplash: Pathophysiology, diagnosis, treatment, and prognosis. Muscle Nerve. 2004;29(6):768-81. [PMID: 15170609] DOI:10.1002/mus.20060

5. Stovner LJ. The nosologic status of the whiplash syndrome: A critical review based on a methodological approach. Spine. 1996;21(23):2735-46. [PMID: 8979319$]$ DOI:10.1097/00007632-199612010-00006

6. Lee J, Giles K, Drummond PD. Psychological disturbances and an exaggerated response to pain in patients with whiplash injury. J Psychosom Res. 1993;37(2):105-10. [PMID: 843986] DOI:10.1016/0022-3999(93)90076-R

7. Sterling M, Jull G, Vicenzino B, Kenardy J, Darnell R. Physical and psychological factors predict outcome following whiplash injury. Pain. 2005;114(1-2):141-48. [PMID: 15733639]

8. Banic B, Petersen-Felix S, Andersen OK, Radanov BP, Villiger PM, Arendt-Nielsen L, Curatolo M. Evidence for spinal cord hypersensitivity in chronic pain after whiplash injury and in fibromyalgia. Pain. 2004;107(1-2):7-15. [PMID: 14715383]

9. Herren-Gerber R, Weiss S, Arendt-Nielsen L, PetersenFelix S, Di Stefano G, Radanov BP, Curatolo M. Modulation of central hypersensitivity by nociceptive input in chronic pain after whiplash injury. Pain Med. 2004;5(4): 366-76. [PMIDL 15563322] DOI:10.1111/j.1526-4637.2004.04055.x

10. Sterling M, Jull G, Vicenzino B, Kenardy J. Sensory hypersensitivity occurs soon after whiplash injury and is associated with poor recovery. Pain. 2003;104(3):509-17. [PMID: 12927623]

11. Sterling M, Treleaven J, Edwards S, Jull G. Pressure pain thresholds in chronic whiplash associated disorder: Further evidence of altered central pain processing. J Musculoskel Pain. 2002;10(3):69-81. DOI:10.1300/J094v10n03 05

12. Nederhand MJ, IJzerman MJ, Hermens HJ, Turk DC, Zilvold G. Predictive value of fear avoidance in developing chronic neck pain disability: Consequences for clinical decision making. Arch Phys Med Rehabil. 2004;85(3): 496-501. [PMID: 15031840] DOI:10.1016/j.apmr.2003.06.019

13. Nieto R, Miró J, Huguet A. The fear avoidance model in whiplash injuries. Eur J Pain. 2009;13(5):518-23.

\section{[PMID: 18640860]}

DOI:10.1016/j.ejpain.2008.06.005

14. Sterling M, Jull G, Kenardy J. Physical and psychological factors maintain long-term predictive capacity postwhiplash injury. Pain. 2006;122(1-2):102-8.

[PMID: 16527397]

15. Stewart MJ, Maher CG, Refshauge KM, Herbert RD, Bogduk N, Nicholas M. Randomized controlled trial of exercise for chronic whiplash-associated disorders. Pain. 2007;128(1-2):59-68. [PMID: 17029788]

16. Stewart MJ. Treatment of chronic whiplash [dissertation]. [Sydney, Australia]: University of Sydney; 2005.

17. Verhagen AP, Scholten-Peeters GG, Van Wijngaarden S, De Bie RA, Bierma-Zeinstra SM. Conservative treatments for whiplash. Cochrane Database Syst Rev. 2007;2:CD003338. [PMID: 17443525]

18. Holm LW, Carroll LJ, Cassidy JD, Skillgate E, Ahlbom A. Expectations for recovery important in the prognosis of whiplash injuries. PLoS Med. 2008;5(5):e105.

[PMID: 18479182]

DOI:10.1371/journal.pmed.0050105

19. Oliveira A, Gevirtz R, Hubbard D. A psycho-educational video used in the emergency department provides effective treatment for whiplash injuries. Spine. 2006;31(15):1652-57. [PMID: 16816758]

DOI:10.1097/01.brs.0000224172.45828.e3

20. Vendrig AA, Van Akkerveeken PF, McWhorter KR. Results of a multimodal treatment program for patients with chronic symptoms after a whiplash injury of the neck. Spine. 2000;25(2):238-44. [PMID: 10685489]

DOI:10.1097/00007632-200001150-00016

21. Berglund A, Bodin L, Jensen I, Wiklund A, Alfredsson L. The influence of prognostic factors on neck pain intensity, disability, anxiety and depression over a 2-year period in subjects with acute whiplash injury. Pain. 2006;125(3): 244-56. [PMID: 16806708]

22. Söderlund A, Lindberg P. Cognitive behavioural components in physiotherapy management of chronic whiplash associated disorders (WAD) - A randomised group study. G Ital Med Lav Ergon. 2007;29(1 Suppl A):A5-11. [PMID: 17650736]

23. Börsbo B, Peolsson M, Gerdle B. Catastrophizing, depression, and pain: Correlation with and influence on quality of life and health-A study of chronic whiplash-associated disorders. J Rehabil Med. 2008;40(7):562-69.

[PMID: 18758674] DOI:10.2340/16501977-0207

24. Kamper SJ, Rebbeck TJ, Maher CG, McAuley JH, Sterling M. Course and prognostic factors of whiplash: A systematic review and meta-analysis. Pain. 2008;138(3):617-29. [PMID: 18407412] 
25. Söderlund A, Lindberg P. Whiplash-associated disordersPredicting disability from a process-oriented perspective of coping. Clin Rehabil. 2003;17(1):101-7. [PMID: 12617385] DOI:10.1191/0269215503cr566oa

26. Jackson T, Pope L, Nagasaka T, Fritch A, Iezzi T, Chen H. The impact of threatening information about pain on coping and pain tolerance. Br J Health Psychol. 2005;10(Pt 3): 441-51. [PMID: 16238858] DOI:10.1348/135910705X27587

27. Moseley GL. Evidence for a direct relationship between cognitive and physical change during an education intervention in people with chronic low back pain. Eur J Pain. 2004;8(1):39-45. [PMID: 14690673] DOI:10.1016/S1090-3801(03)00063-6

28. Moseley GL. A pain neuromatrix approach to patients with chronic pain. Man Ther. 2003;8(3):130-40. [PMID: 12909433] DOI:10.1016/S1356-689X(03)00051-1

29. Moseley GL. Joining forces-Combining cognition-targeted motor control training with group or individual pain physiology education: A successful treatment for chronic low back pain. J Man Manip Ther. 2003;11(2):88-94. DOI:10.1179/106698103790826383

30. Moseley GL. Combined physiotherapy and education is efficacious for chronic low back pain. Austr J Physiother. 2002;48(4):297-302. [PMID: 12443524]

31. Moseley GL, Nicholas MK, Hodges PW. A randomized controlled trial of intensive neurophysiology education in chronic low back pain. Clin J Pain. 2004;20(5):324-30. [PMID: 15322439] DOI:10.1097/00002508-200409000-00007

32. Moseley GL. Widespread brain activity during an abdominal task markedly reduced after pain physiology education: fMRI evaluation of a single patient with chronic low back pain. Austr J Physiother. 2005;51(1):49-52.

[PMID: 15748125]

DOI:10.1016/j.apmr.2010.04.020

33. Meeus M, Nijs J, Van Oosterwijck J, Van Alsenoy V, Truijen S. Pain physiology education improves pain beliefs in patients with chronic fatigue syndrome compared with pacing and self-management education: A double-blind randomized controlled trial. Arch Phys Med Rehabil. 2010; 91(8):1153-59. [PMID: 20684894]

34. Nijs J, Van Oosterwijck J, De Hertogh W. Rehabilitation of chronic whiplash: Treatment of cervical dysfunctions or chronic pain syndrome. Clin Rheumatol. 2009;28(3):243-51. [PMID: 19160000]

DOI:10.1007/s10067-008-1083-X

35. Borchgrevink GE, Smevik O, Nordby A, Rinck PA, Stiles TC, Lereim I. MR imaging and radiography of patients with cervical hyperextension-flexion injuries after car accidents. Acta Radiol. 1995;36(4):425-28. [PMID: 7619624$]$
36. Deans GT, Magalliard JN, Kerr M, Rutherford WH. Neck sprain: A major cause of disability following car accidents. Injury. 1987;18(1):10-12. [PMID: 3440606] DOI:10.1016/0020-1383(87)90375-5

37. Hildingsson C, Hietala SO, Toolanen G. Scintigraphic findings in acute whiplash injury of the cervical spine. Injury. 1989;20(5):265-66. [PMID: 2613307] DOI:10.1016/0020-1383(89)90164-2

38. Ronnen HR, De Korte PJ, Brink PR, Van der Bijl HJ, Tonino AJ, Franke CL. Acute whiplash injury: Is there a role for MR imaging?-A prospective study of 100 patients. Radiology. 1996;201(1):93-96. [PMID: 8816527

39. Vernon H, Mior S. The Neck Disability Index: A study of reliability and validity. J Manipulative Physiol Ther. 1991; 14(7):409-15. [PMID: 1834753]

40. Vernon H. The Neck Disability Index: State-of-the-art, 1991-2008. J Manipulative Physiol Ther. 2008;31(7): 491-502. [PMID: 18803999] DOI:10.1016/j.jmpt.2008.08.006

41. Whiteside A, Hansen S, Chaudhuri A. Exercise lowers pain threshold in chronic fatigue syndrome. Pain. 2004;109(3): 497-99. [PMID: 15157711]

42. Johnston V, Jimmieson NL, Jull G, Souvlis T. Quantitative sensory measures distinguish office workers with varying levels of neck pain and disability. Pain. 2008;137(2):257-65. [PMID: 17964075]

43. Farasyn A, Meeusen R. Pressure pain thresholds in healthy subjects: Influence of physical activity, history of lower back pain factors and the use of endermology as a placebolike treatment. J Bodywork Mov Ther. 2003;7(1):53-61. DOI:10.1016/S1360-8592(02)00050-5

44. Vanderweeën L, Oostendorp RA, Vaes P, Duquet W. Pressure algometry in manual therapy. Man Ther. 1996;1(5): 258-65. [PMID: 11440515] DOI:10.1054/math.1996.0276

45. De Kock M. [Whiplash associated disorders of “WAD”]. Tijdschrift voor Geneeskunde. 1997;53(24):1665-70. Dutch.

46. Michiels K, Beeckmans K, Kiekens C. Psychologische problemen bij patiënten met een laat whiplashsyndroom: Oorzaak of gevolg? Tijdschrift voor Geneeskunde. 2000; 56(9):647-54. Dutch. DOI:10.2143/TVG.56.9.5000732

47. Ligjaerde O, Føreland AR. Direct assessment of improvement in winter depression with a visual analogue scale: High reliability and validity. Psychiatry Res. 1998;81(3): 387-92. [PMID: 9925190] DOI:10.1016/S0165-1781(98)00119-X

48. Kori SH, Miller RP, Todd DD. Kinesiophobia: A new view of chronic pain behaviour. Pain Manag. 1990;3:35-43.

49. Silver A, Haeney M, Vijayadurai P, Wilks D, Pattrick M, Main CJ. The role of fear of physical movement and activity in chronic fatigue syndrome. J Psychosom Res. 2002;52(6): 
485-93. [PMID: 12069873]

DOI:10.1016/S0022-3999(01)00298-7

50. Vlaeyen JW, Kole-Snijders AM, Boeren RG, Van Eek H. Fear of movement/(re)injury in chronic low back pain and its relation to behavioral performance. Pain. 1995;62(3): 363-72. [PMID: 8657437]

51. Crombez G, Vlaeyen JW, Heuts PH, Lysens R. Pain-related fear is more disabling than pain itself: Evidence on the role of pain-related fear in chronic back pain disability. Pain. 1999;80(1-2):329-39. [PMID: 10204746]

52. Goubert L, Crombez G, Van Damme S, Vlaeyen JW, Bijttebier P, Roelofs J. Confirmatory factor analysis of the Tampa Scale for Kinesiophobia: Invariant two-factor model across low back pain patients and fibromyalgia patients. Clin J Pain. 2004;20(2):103-10. [PMID: 14770050] DOI:10.1097/00002508-200403000-00007

53. Sullivan MJ, Bishop SR, Pivik J. The pain catastrophizing scale: Development and validation. Psychol Assess. 1995; 7(4):524-32. DOI:10.1037/1040-3590.7.4.524

54. Van Damme S, Crombez G, Bijttebier P, Goubert L, Van Houdenhove B. A confirmatory factor analysis of the Pain Catastrophizing Scale: Invariant factor structure across clinical and non-clinical populations. Pain. 2002;96(3): 319-24. [PMID: 11973004]

55. Van Damme S, Crombez G, Vlaeyen JWS, Goubert L, Van den Broeck A, Van Houdenhove B. De Pain Catastrophizing Scale: Psychometrische karakteristieken en normering. Gedragstherapie. 2000;33:209-20. Dutch.

56. Kraaimaat FW, Bakker AH, Evers AW. Pijncoping strategieën bij chronische pijn patiënten. De ontwikkeling van de Pijn-Coping-Inventarisatielijst (PCI). Gedragstherapie. 1997; 22:267-77. Dutch.

57. Kraaimaat FW, Evers AW. Pain-coping strategies in chronic pain patients: Psychometric characteristics of the pain-coping inventory (PCI). J Behav Med. 2003;10(4): 343-63. [PMID: 14734263] DOI:10.1207/S15327558IJBM1004 5

58. Lanser K. Cervicale segmentale instabiliteit. Ned Tijdschr Man Ther. 1988;7:82-84. Dutch.

59. Verhagen AP, Lanser K, De Bie RA, De Vet HC. Whiplash: Assessing the validity of diagnostic tests in a cervical sensory disturbance. J Manip Physiol Ther. 1996;19(8):508-12. [PMID: 8902661]

60. Verhagen AP, Lanser K. Whiplash en een cervicale segmentale functiestoornis: Beschrijving van twee diagnostische tests. In: Vaes P, Kwakkel G, Smits-Engelsman, BC, Verhagen AP, editors. Jaarboek Fysiotherapie 2002. Houten (the Netherlands): Bohn Stafleu van Loghum; 2002. p. 144-53.

61. Balster SM, Jull GA. Upper trapezius activity during the brachial plexus tension test in asymptomatic subjects. Man
Ther. 1997;2(3):144-49. [PMID: 11440527]

DOI:10.1054/math.1997.0294

62. Clarkson HM, Gilewich GB. Musculoskeletal assessment: Joint range of motion and manual muscle strength. Baltimore (MD): Williams \& Wilkins; 1989.

63. Coppieters M, Stappaerts K, Janssens K, Jull G. Reliability of detecting "onset of pain” and "submaximal pain” during neural provocation testing of the upper quadrant. Physiother Res Int. 2002;7(3):146-56. [PMID: 12426912] DOI:10.1002/pri.251

64. Butler DS, Moseley GL. Explain pain. Adelaide (Australia): NOI Group Publishing; 2003.

65. Moseley GL. Unraveling the barriers to reconceptualization of the problem in chronic pain: The actual and perceived ability of patients and health professionals to understand the neurophysiology. J Pain. 2003;4(4):184-89. [PMID: 14622702] DOI:10.1016/S1526-5900(03)00488-7

66. Meeus M, Nijs J, Elsemans KS, Truijen S, De Meirleir K. Development and properties of the Dutch neurophysiology of pain test in patients with chronic fatigue syndrome. J Muscoskel Pain. 2010;18(1):58-65. DOI:10.3109/10582450903495908

67. Cohen J. Statistical power analysis for the behavioral sciences. Hillsdale (NJ): L. Erlbaum Associates; 1988.

68. Zusman M. Forebrain-mediated sensitization of central pain pathways: "Non-specific" pain and a new image for MT. Man Ther. 2002;7(2):80-88. [PMID: 12151244$]$ DOI:10.1054/math.2002.0442

69. McClune T, Burton AK, Waddel G. Whiplash associated disorders: A review of the literature to guide patient information and advice. Emerg J. 2002;19(6):499-506.

[PMID: 12421771]

DOI:10.1136/emj.19.6.499

70. McClune T, Burton AK, Waddel G. Evaluation of an evidence based patient educational booklet for management of whiplash associated disorders. Emerg Med J. 2003;20(6): 514-17. [PMID: 14623835]

DOI:10.1136/emj.20.6.514

71. Vangronsveld K, Peters M, Goossens M, Linton S, Vlaeyen J. Applying the fear-avoidance model to the chronic whiplash syndrome. Pain. 2007;130:258-61. [PMID: 17531388]

72. Houben RM, Gijsen A, Peterson J, De Jong PJ, Vlaeyen JW. Do health care providers' attitudes towards back pain predict their treatment recommendations? Differential predictive validity of implicit and explicit attitude measures. Pain. 2005;114(3):491-98. [PMID: 15777874]

Submitted for publication December 31, 2009. Accepted in revised form July 12, 2010. 
VAN OOSTERWIJCK et al. Pain neurophysiology education in chronic whiplash

This article and any supplementary material should be cited as follows:

Van Oosterwijck J, Nijs J, Meeus M, Truijen S, Craps J, Van den Keybus N, Paul L. Pain neurophysiology education improves cognitions, pain thresholds, and movement performance in people with chronic whiplash: A pilot study. J Rehabil Res Dev. 2011;48(1):43-58.

DOI:10.1682/JRRD.2009.12.0206

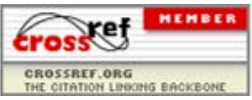


